West African Papers

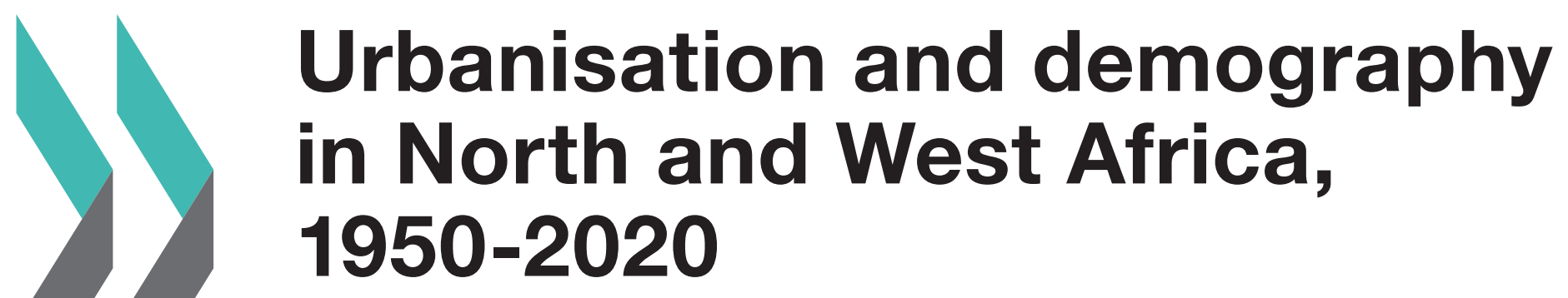

NOVEMBER 2021 NO. 33

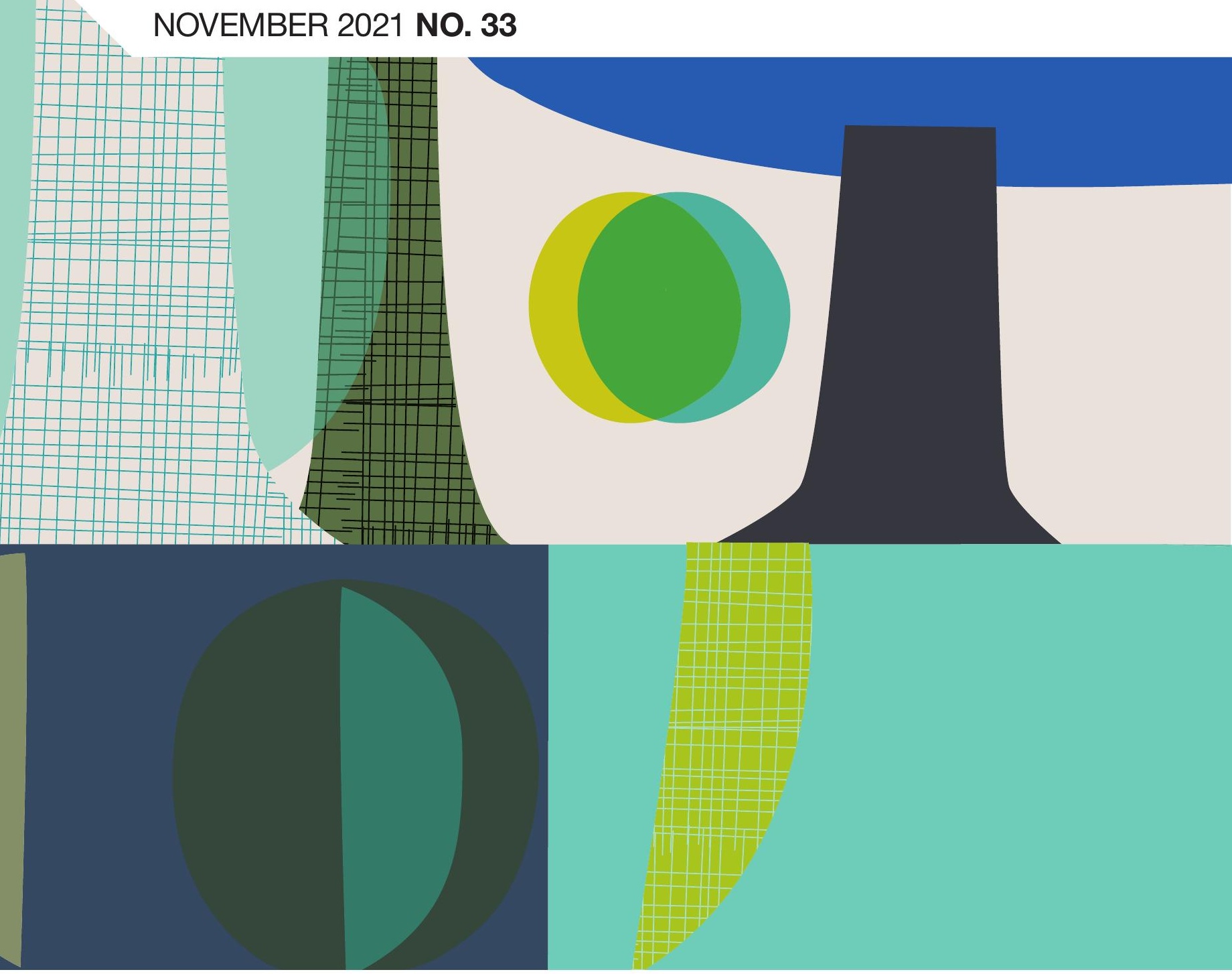




\section{URBANISATION AND DEMOGRAPHY IN NORTH AND WEST AFRICA, 1950-2020}

This paper has been prepared by

Olivier J. Walther

Sahel Research Group, University of Florida

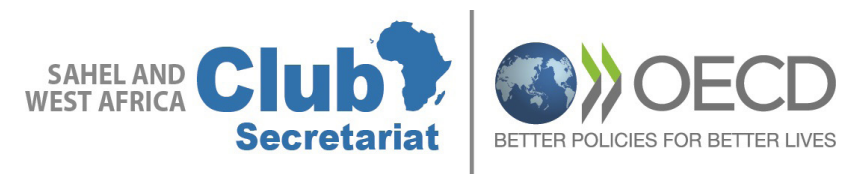




\section{WEST AFRICAN PAPERS}

The West African Papers series explores African socio-economic, political and security dynamics from a regional and multidisciplinary perspective. It seeks to stimulate discussion and gather information to better anticipate the changes that will shape future policies. The series is designed for a wide audience of specialists, development practitioners, decision makers and the informed public. Papers are available in English and/or French, and summaries are available in both languages. Initiated by the Sahel and West Africa Club (SWAC) to highlight and promote West African issues, the work presented is prepared by its Secretariat, Members and partners, other OECD departments, related international organisations, associated experts and researchers.

Please cite this publication as:

Walther, O. (2021), "Urbanisation and demography in North and West Africa, 1950-2020", West African Papers, No. 33, OECD Publishing, Paris.

https://doi.org/10.1787/4fa52e9c-en

Author contact: owalther@ufl.edu

West African Papers

ISSN 2414-2026

This work is published under the responsibility of the Secretary-General of the OECD. The opinions expressed and arguments employed herein do not necessarily reflect the official views of OECD member countries.

This document, as well as any data and map included herein, are without prejudice to the status of or sovereignty over any territory, to the delimitation of international frontiers and boundaries and to the name of any territory, city or area.

Authorised for publication by Laurent Bossard, Director, Sahel and West Africa Club Secretariat (SWAC/OECD).

Photo credits: Cover @ Delphine Chedru 


\begin{abstract}
This brief presents a factual and retrospective analysis of the relationships between urbanisation and demography in North Africa and West Africa. It shows that the process of demographic transition is now fully underway in this region. North of the Sahara the new demographic equilibrium features a birth rate higher than expected, according to theoretical model predictions, resulting in continuous population growth. Over $70 \%$ of the population now lives in cities, a number that is expected to continue to rise in the coming decades. South of the Sahara all countries have seen death rates plummet, followed by a decrease in birth rates. The gap between the change in the two variables has contributed to spectacular natural growth in the space of a few decades. This growth is occurring in parallel with a redistribution of populations to urban areas, which are now home to close to one of every two inhabitants. West African urbanisation is likely to accelerate the social, economic and political changes that favour the demographic transition. One of the main challenges facing the region is the question of how to reduce the regional variations seen in fertility rates between the continent's urban and rural areas.
\end{abstract}

Key words : demography, population, birth rate, urbanisation, West Africa JEL Codes : N37, N97, Q56

\begin{abstract}
About the author
Olivier J. Walther is an Assistant Professor in the Geography Department at the University of Florida in the United States. Dr Walther received his Ph.D. in Geography from the University of Lausanne. His research focuses on trade and conflicts in West Africa as seen through the lens of social networks analyses. His work has been funded by NASA, the United Nations, the National Science Foundation, the OECD, and the European Union. Within the Sahel Research Group of the University of Florida, he co-ordinates research on regional insecurity for the Sahel and West Africa Club (SWAC/OECD).
\end{abstract}

\title{
Note to readers
}

This publication has received additional funds from the Swiss Agency for Development and Cooperation (SDC). 


\section{The Sahel and West Africa Club}

The Sahel and West Africa Club (SWAC) is an independent international platform. Its Secretariat is hosted at the Organisation for the Economic Co-operation and Development (OECD). Its mission is to promote regional policies that will improve the economic and social well-being of the people in the Sahel and West Africa. Its objectives are to produce and collect data, draft analyses and facilitate strategic dialogue in order to nurture and promote public policies in line with rapid developments in the region. It also promotes regional co-operation as a tool for sustainable development and stability. Its current areas of work are food dynamics, cities and territories, and security.

SWAC Members and partners include: Austria, Belgium, Canada, CILSS (Permanent Interstate Committee for Drought Control in the Sahel), the ECOWAS (Economic Community of West African States) Commission, the European Commission, France, Luxembourg, the Netherlands, Norway, Switzerland, the UEMOA (West African Economic and Monetary Union) Commission and the United States. SWAC has a memorandum of understanding with the University of Florida Sahel Research Group.

More information:

www.oecd.org/swac 


\section{Table of contents}

INTRODUCTION 7

DEMOGRAPHIC TRANSITION

DEMOGRAPHIC CHANGES IN NORTH AND WEST AFRICA

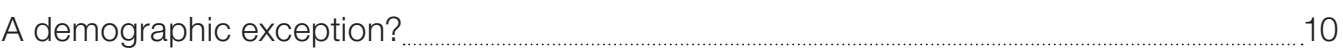

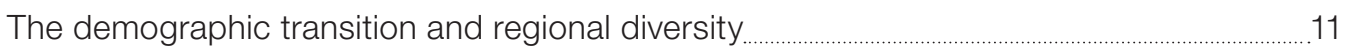

Convergence of birth and death rates in North and West Africa $\ldots$

National demographic growth $\quad 15$

A drop in the fertility rate throughout West Africa $\quad 20$

DEMOGRAPHY AND URBANISATION $\quad 22$

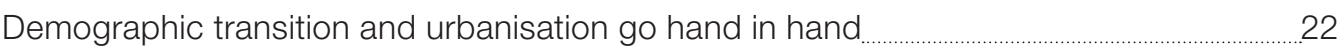

The growth of urbanisation $\quad 23$

Changes by $2050 \quad 26$

OUTLOOK 28

REFERENCES $\quad 29$

Figure 1 Theoretical phases of demographic transition _ ............................................................. 8

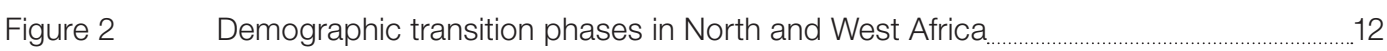

Figure 3 Demographic transition in North Africa and the Sahel, 1950-2020 _................................13

Figure 4 Convergence of birth and death rates in North Africa and Cabo Verde, 1960-2020 _.......... 14

Figure 5 Convergence of birth and death rates in the Sahel, 1960-2020

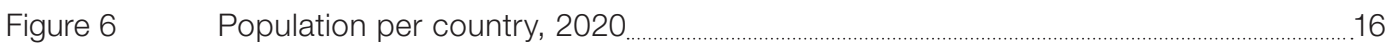

Figure 7 Demographic growth and total population of North Africa and the Sahel, 1950-2020 _...... 17

Figure 8 Demographic growth rate per country, 1950-2020 _ 18

Figure $9 \quad$ Change in population per country (in millions) _............................................................ 19

Figure 10 Fertility rates of the most advanced West African countries, 1960-2020 _...................... 20

Figure 11 Fertility rates of the least advanced West African countries, 1960-2020 21

Figure 12 Fertility and urbanisation in North and West Africa, 2020 …................................... 22

Figure 13 Urbanisation rate per country, 2020 _ 23

Figure 14 Regional urbanisation rates, 1950-2020 _................................................................. 24

Figure 15 Settlement dynamics in West Africa, 1950-2020 …......................................................... 24

Figure 16 Urban population growth and figures per region, 1950-2020 ………….......................... 25

Figure 17 Rural population growth and figures per region, 1950-2020 26

Figure 18 Population growth in the Sahel versus North Africa, 1950-2050_ 27

Figure 19 Projected number of inhabitants per country, 1950-2050 (in millions of people) _......27 



\section{Introduction}

Africa is experiencing demographic growth that is unprecedented in the history of the continent. If the growth trend continues, the population of the continent will reach 2.5 billion by 2050, or double the current number of inhabitants (United Nations, 2019[1]). In addition to this demographic growth, urbanisation is increasing at a spectacular rate. While Africa's urban population grew from 27 million in 1950 to 567 million in 2015, it is the continent's cities that will absorb two-thirds of the projected demographic growth by 2050 (OECD/SWAC, 2020[2]).

Driven by strong natural growth and intense regional migrations, urbanisation has fuelled transformations that go beyond the mere geographical distribution of the population and its demographic structure. The growth and multiplication of cities is also synonymous with significant changes in the social organisation of African populations, their economic activities and political equilibrium. As is the case in the rest of the world, urbanisation enables more timely access to health and education services as well as to markets and institutions that foster human rights and democracy.

Given that context, this paper presents a factual and retrospective analysis of the relationships between urbanisation and demography in North and West Africa. It provides an update to the work done by the Sahel and West Africa Club (SWAC) of the OECD on human settlement (OECD/SWAC, 2014[3]; 2013[4]) and urbanisation (Moriconi-Ebrard, Harre and Heinrigs, 2016[5]; OECD/SWAC, 2020[2]) over the past decade or so. It outlines the process of demographic transition from an equilibrium of high birth and death rates to a new one marked by low rates. Based on a long-term analysis of regional trends, the paper then discusses to what degree the theoretical stages of a demographic transition apply to countries in North and West Africa. It then illustrates the relationships between urbanisation and fertility, and sheds light on some major, projected demographic changes by 2050. 


\section{Demographic transition}

The historic evolution of the global population is determined by two demographic factors: the number of births and the number of deaths. Until the end of the 18th century, all of the countries in the world experienced the high birth rates and death rates characteristic of a traditional demographic regime, in which households compensated for the very large number of deaths with birth rates close to the biological maximum. During that time, the precarious balance between birth and death rates was in constant peril due to conflicts, epidemics and famines. Consequently, there was very little population growth.

Over the course of the last two centuries, the industrial revolution and urbanisation, combined with improvements in sanitation and progress in medical science have caused the mortality rate to plummet; this was followed by a dramatic drop in the birth rate. This shift from a traditional demographic regime to a new equilibrium marked by very low birth and death rates is known as a demographic transition (Figure 1). This process consists of three major theoretical phases.

Figure 1.

Theoretical phases of demographic transition

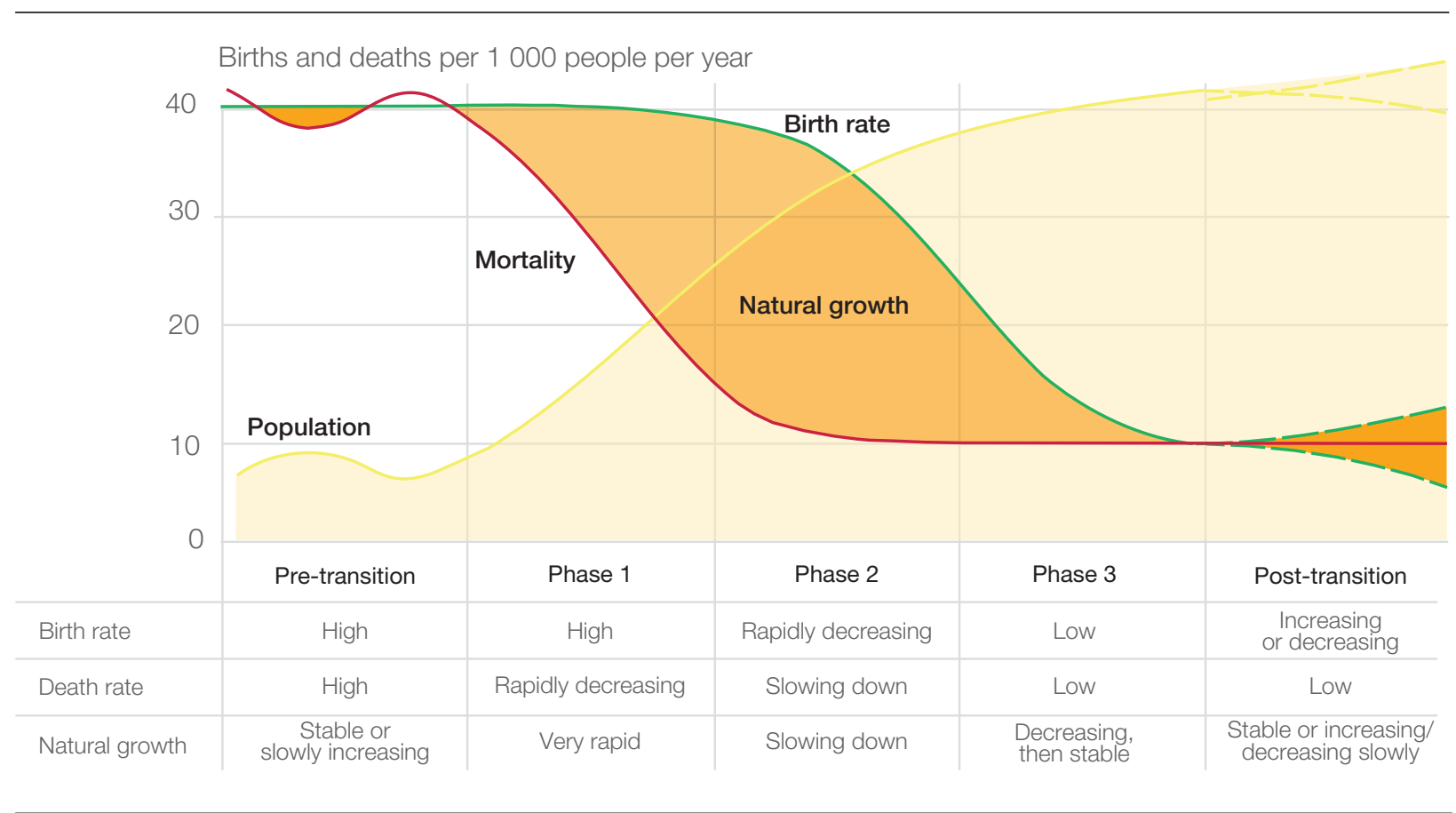

Sources: Our World in Data (2021[6]) and Doignon (2020[7]), adapted by the author. 
- In the first phase the death rate, expressed as the number of deaths per 1000 inhabitants per year, drops quickly; this is especially true with respect to infant mortality. Access to medical care and a better diet result in the number of deaths dropping from $40 \%$ o to $15 \%$. Also in the first phase, the birth rate - expressed as the number of births per 1000 inhabitants per year - remains quite high at about 40\%. The observed difference between the decrease in the death rate, as compared with the drop in the birth rate, is due to the inertia of a number of moral values and the slow pace of change in family models, which still favour large families and limit women's emancipation.

- In the second phase of the demographic transition, social and moral changes, an increase in non-agricultural employment and access to modern contraception foster a rapid decline in the birth rate, which drops from $40 \%$ to $25 \%$. The death rate continues to decline, but at a slower rate, and sits at 10-15\%o. Natural population growth, which peaks during the first phase of the transition, also slows down due to the sharp drop in the number of births.

- The third phase of the demographic transition is marked by a gradual convergence of the birth and death rates, which level out at about $10 \%$. Consequently, the level of natural population growth is low during this phase, and this gradually produces a new demographic equilibrium.

Once the demographic transition process is complete, birth and death rates are at low levels that are synonymous with demographic stability. Although the change in population in the pre-transition phase was dictated by the mortality rate, it is the birth rate that will now determine any demographic changes. In some countries, worsening economic conditions can result in demographic decline if international emigration does not compensate for the drop in the birth rate. In others, a change in religious norms can encourage some households to have more children, resulting in slight population growth. 


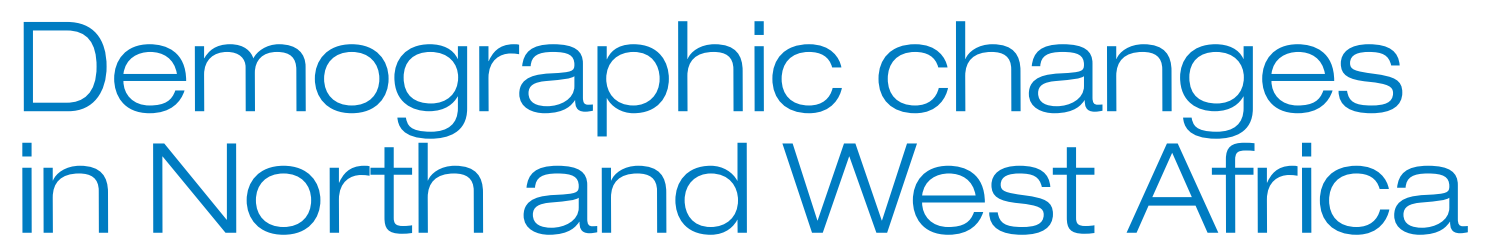

The process of demographic transition is marked by national and regional variations due to differences in social, political and economic contexts. A lower death rate is fostered by urbanisation, for example, which encourages access to health and education services; and by a shift from an agriculturebased economy to one that is based on industry or services. Public policy can also result in lower birth rates, either through coercive means as in China, or through family planning incentives, as in Bangladesh.

\section{A DEMOGRAPHIC EXCEPTION?}

Due to the diversity of national and regional situations, it is important to know the degree to which the theoretical phases of demographic transition apply to the countries of North and West Africa. A study of the change in the birth and death rates from 1960 to 2020 shows that all countries in the region are undergoing the demographic transition to varying degrees. In 2020, none of the countries were showing signs of the high birth and death rates characteristic of a traditional demographic regime (pre-transition). The demographic transition follows the general model observed elsewhere in the world. However, two important differences were seen with respect to births. As compared to Southeast Asia and Latin America, the drop in the fertility rate came later and was slower in North and West Africa. These specifics, which were observed throughout the continent, encouraged some authors to suggest a type of African exception in the 2010s (Bongaarts, 2017[8]).

However, more recent data suggest that even though the fertility rate is not dropping as quickly as in other places, the decline continues into the current decade and is bringing about a new demographic equilibrium on the continent in the medium term (Lerch, 2019[9]). In other words, Africa is not an exception when compared to other parts of the world even if, in some countries, the birth rate is still higher than the theoretical model predictions for each of the phases. The relatively slow drop in the fertility rate in sub-Saharan Africa, and in rural areas in particular, is producing a significant increase in the total population, a number determined by the observed difference between the number of births and deaths. 


\section{THE DEMOGRAPHIC TRANSITION AND REGIONAL DIVERSITY}

An analysis of demographic changes makes clear that there are three major groups of countries: (1) three of the Sahel's poorest and least urbanised countries, (2) most other Sahel and West African countries, (3) Cabo Verde and the countries in North Africa.

- Niger, Chad and Mali are in the first phase of demographic transition, with birth rates that are still above $40 \%$ and a rapidly decreasing death rate (Figure 2). This situation is more favourable to natural national population growth. It is not surprising at this point to note that these three countries are experiencing some of the highest demographic growth rates on the continent: 3.8\% in Niger and 3.0\% in both Chad and Mali in 2019. These growth rates doubled the population in less than 19 years in Niger, and in less than 24 years in Chad and Mali. With 8-12 deaths per 1000 inhabitants, the death rate in these three countries is still lower than the figures considered to be representative of the first phase of the transition (15-40\%), according to the theoretical model. On the other hand, the birth rate of 41-45 births per 1000 inhabitants is higher than the theoretical model figures (40\%). Such rates are not uncommon in the region: North African countries and Cabo Verde had birth rates above 40\% until the beginning of the 1980s (Figure 4).

- The other Sahel countries and West Africa are in the second phase of the demographic transition. This phase is marked by a sharp drop in the birth rate and slowdown in the declining death rate. Nigeria and Sierra Leona are the only countries whose rates match the theoretical model, with a birth rate of $25-40 \%$ and a death rate at $10-15 \%$. The death rates in the other countries are between 5 and 10\%, which is lower than the model's prediction for that phase (10-15\%o), a sign that heralds in the next phase of the demographic transition.

- Cabo Verde and the North African countries are further along in the demographic transition. Their death rates are at less than 10\%, which corresponds, overall, to the theoretical model's post-transition figures. However, their crude birth rate sits at between 17 and 23\%o, which is characteristic of the third phase of the transition. Due to the relatively high birth rate, the natural population growth in these countries is higher than in those that have reached a new demographic equilibrium of around 10 births and deaths per 1000 inhabitants, as in western Europe. 
Figure 2.

Demographic transition phases in North and West Africa

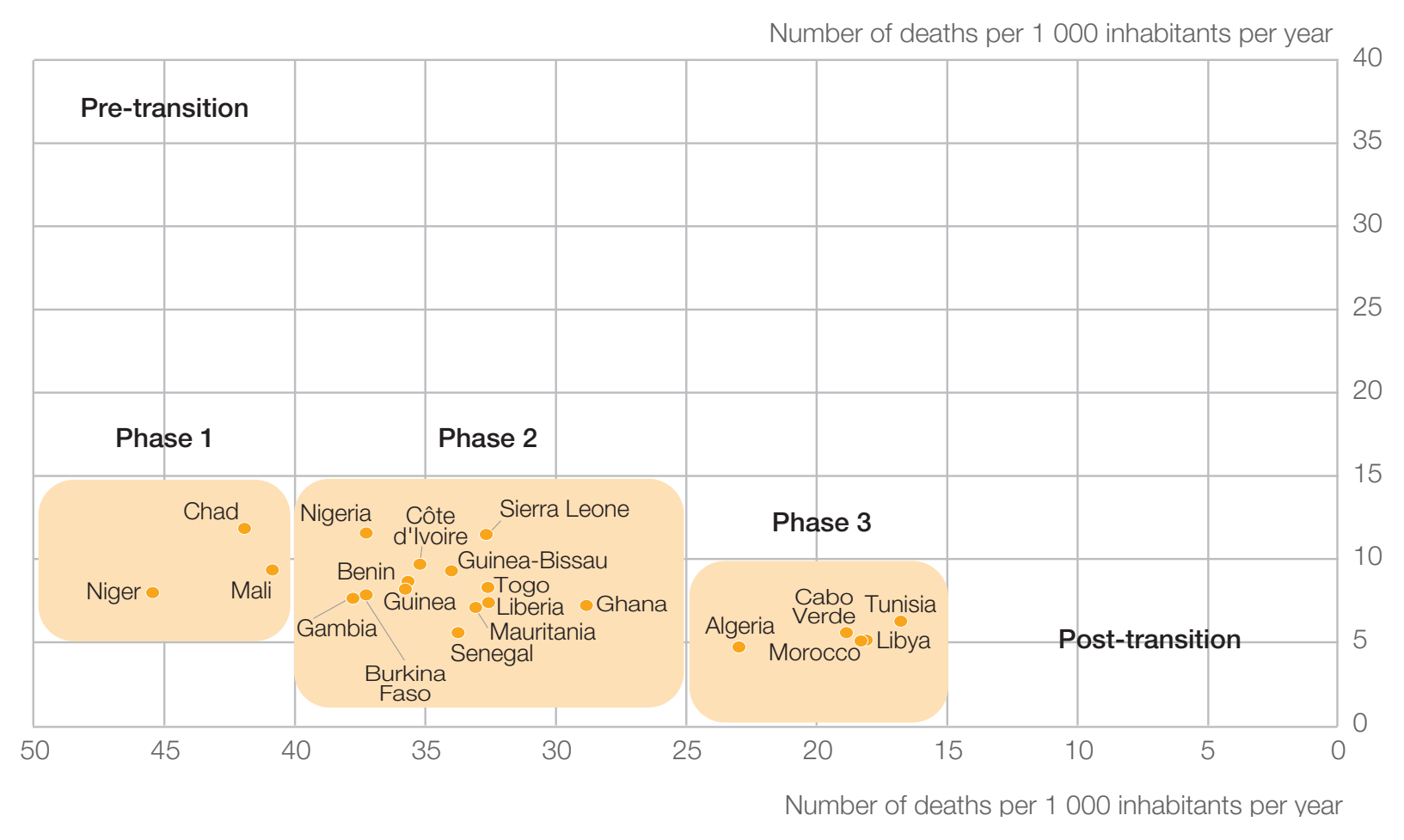

Source: United Nations (2019[1]). Author's calculations.

Significant differences were seen on both sides of the Sahara in terms of the timeline of the demographic transition (Figure 3). In Morocco, Algeria, Tunisia, and Libya the decline in the birth rate, which began in the 1960s, is one of the fastest the world has seen. It took almost two centuries for Sweden to come to a new demographic equilibrium (1750-1980), while in South Korea the process took sixty years (1920-1980) and only fifty years in some North African countries, such as Tunisia (1950-2000). In Sahel countries, the birth rate was stable or increasing slightly until the 2000s, but has been plummeting ever since. There was a rapid and continuous decrease in the death rate in the two regions, but it has levelled out at very low levels, close to 10\% in the Sahel and 5\% in North Africa. 
Figure 3.

Demographic transition in North Africa and the Sahel, 1950-2020

\section{Number of births or deaths per 1000 inhabitants per year}

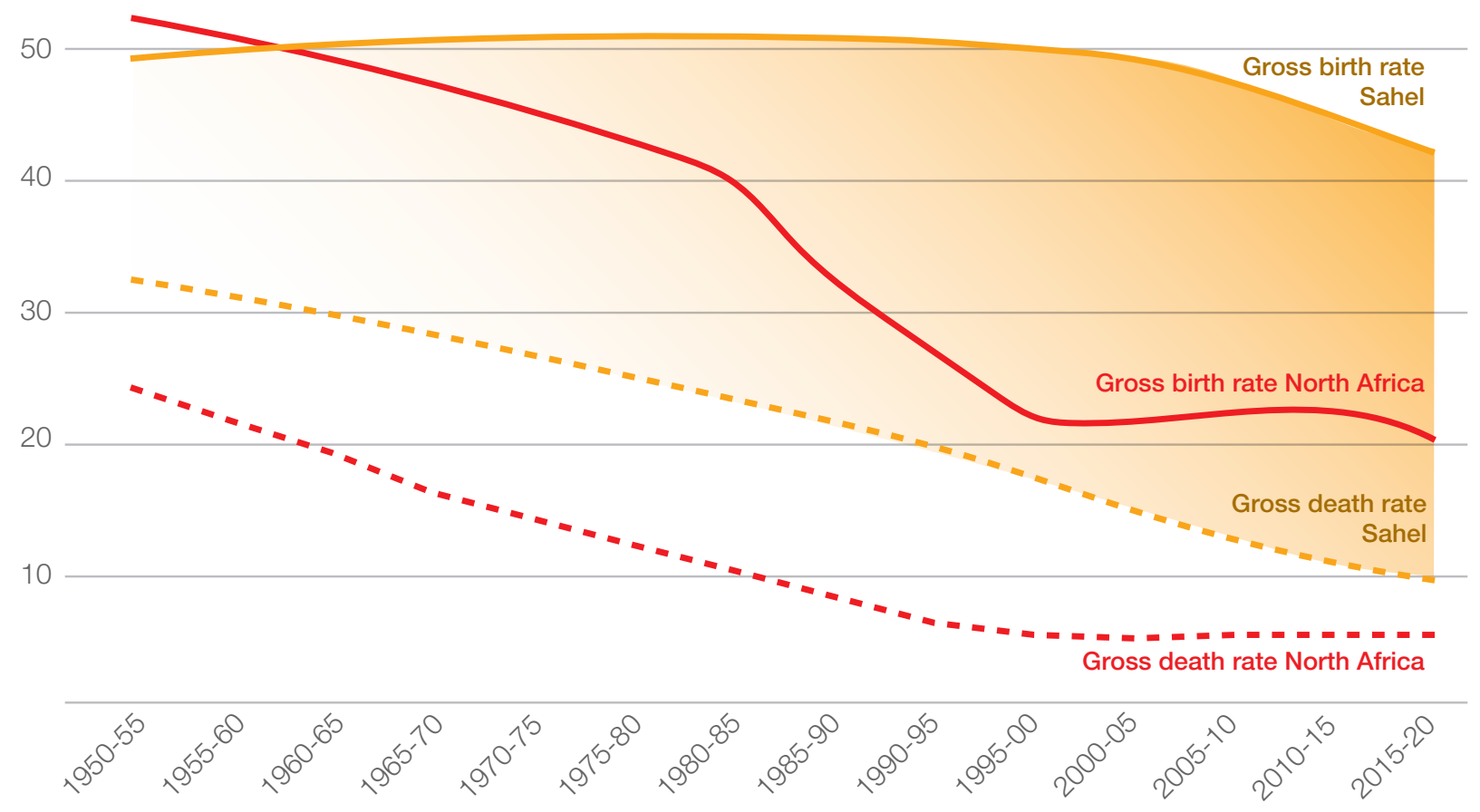

Source: OECD/SWAC (2014[3]). Updated by the author using United Nations data (2019[1]).

\section{CONVERGENCE OF BIRTH AND DEATH RATES IN NORTH AND WEST AFRICA}

The convergence over time of the birth and death rates is particularly clear when the yearly values for each rate, per country, are considered for the past sixty years. Although their birth and death rates were very different in 1960, North African countries and Cabo Verde followed a path of convergence that gradually resulted in a new equilibrium in 2020 (Figure 4). The decline in the birth rate is less linear and continuous than the decrease in the death rate. The number of births per 1000 inhabitants increased in Cabo Verde between 1975 and 1985, in Tunisia between 2005 and 2014, and starting in the 2000s in Algeria (Doignon, 2020[7]). 
Figure 4.

Convergence of birth and death rates in North Africa and Cabo Verde, 1960-2020

60 Number of births and deaths per 1000 inhabitants per year $\quad$ Algeria Cabo Verde
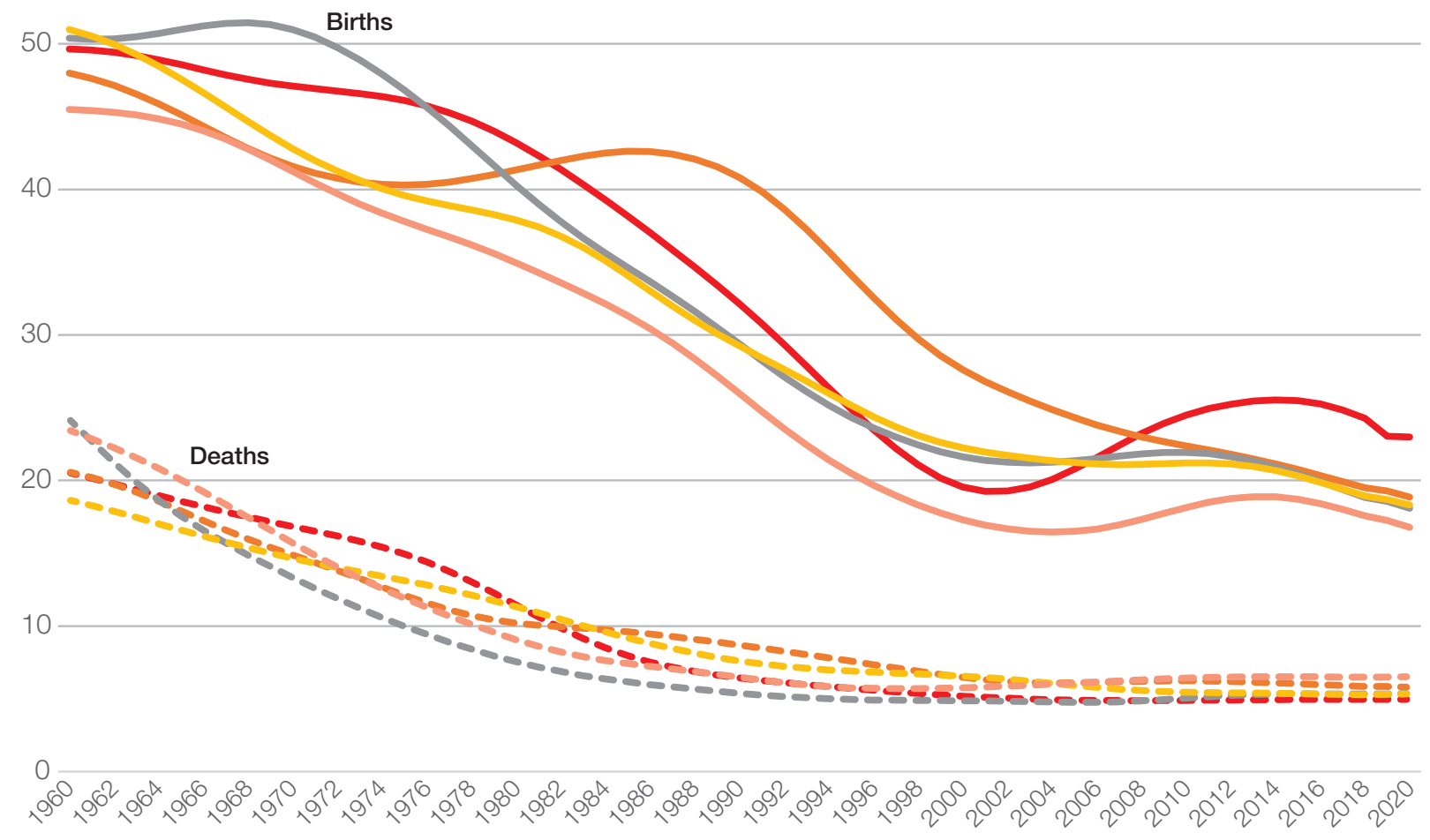

Source: United Nations (2019[1]). Author's calculations.

Demography in the Sahel countries also converged (Figure 5). The decrease in the death rate happened quickly in all countries. The birth rate also dropped gradually, except in Chad, where there was a continuous increase in the number of births until the year 2000. Although the transition in Niger started at a later date than in the other countries, its progress was no less rapid, particularly in terms of the death rate. Although it recorded more than 26 deaths per 1000 inhabitants in 1980, that number dropped to 18 in 2000 and to 8 in 2020. In Niger, the birth rate is higher than elsewhere but has nonetheless dropped significantly from more than 53\% in 2000 to 46\%o in 2020 . 
Figure 5.

Convergence of birth and death rates in the Sahel, 1960-2020

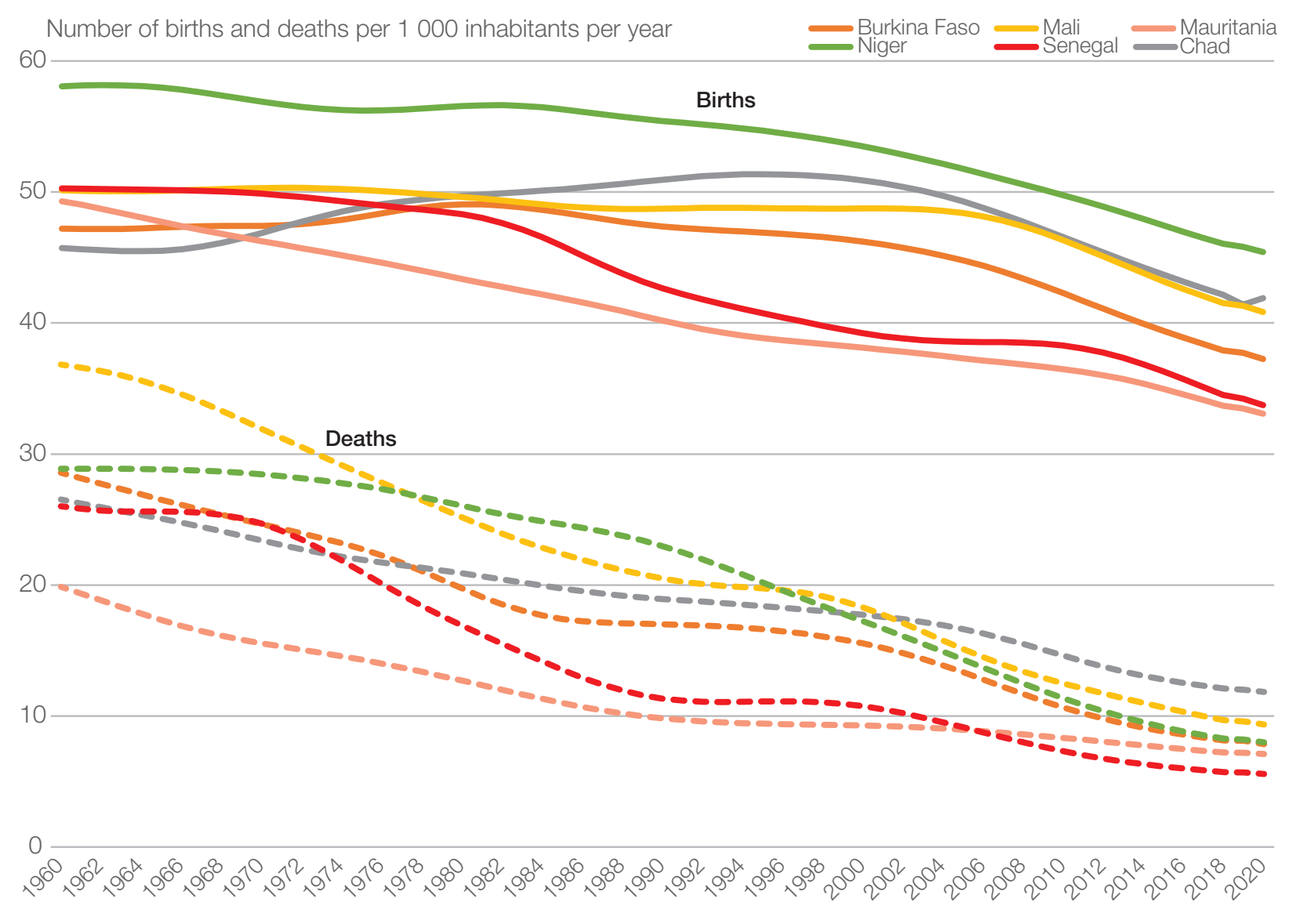

Sources: United Nations (2019[1]). Author's calculations.

\section{NATIONAL DEMOGRAPHIC GROWTH}

In 2020, the population of the eight Sahara-Sahel countries was 166 million people, as compared with 132 million in 2010. Algeria, Libya, Morocco, and Tunisia have close to 100 million inhabitants, or 1.5 times more than the population of their four Sahel neighbours namely Chad, Mali, Mauritania and Niger (66 million) (Figure 6). 
Figure 6.

Population per country, 2020

\section{North Africa (100 million inhabitants)}

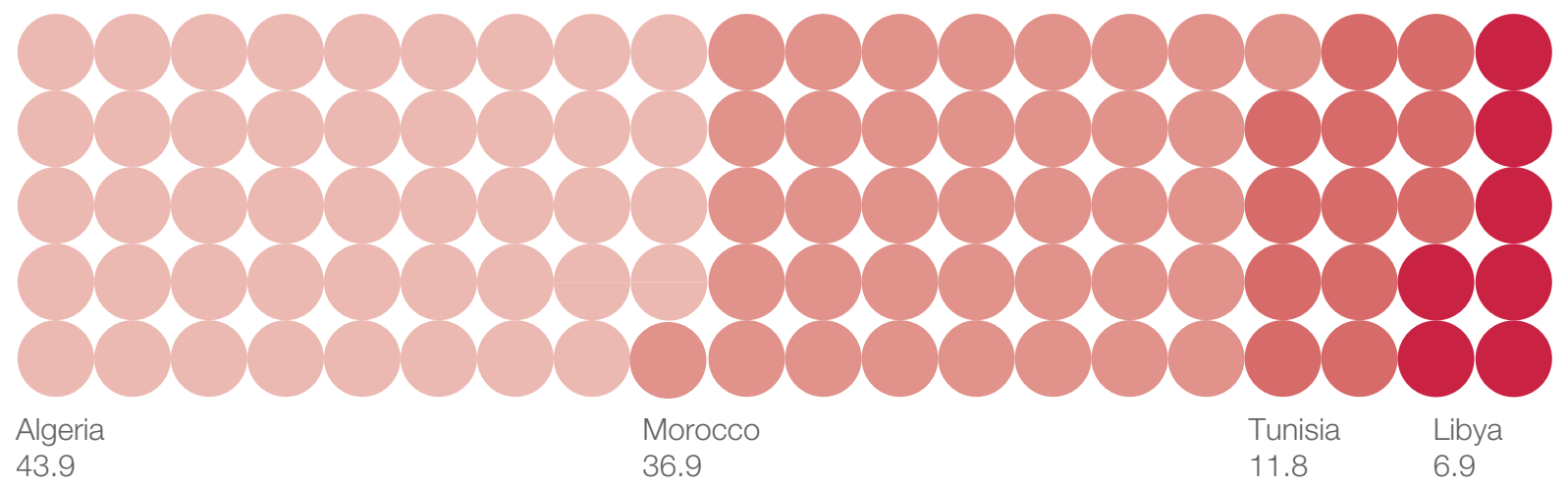

\section{Sahel (66 million inhabitants)}

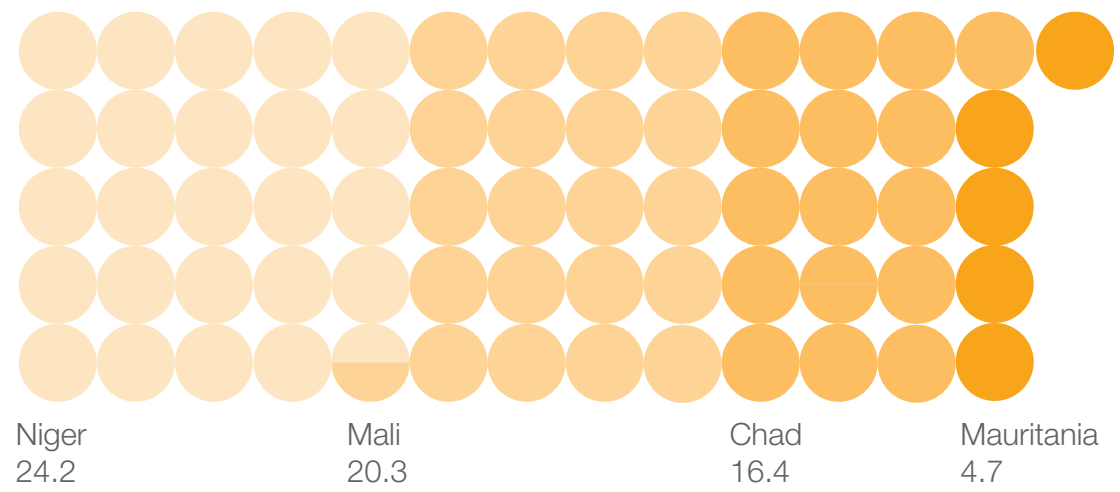

$=1$ million

Source: OECD/SWAC (2014[3]). Updated by the author using United Nations (2019[1]).

Until the mid-1980s, demographic growth in the four North African countries (Algeria, Libya, Morocco, and Tunisia) was higher than it was south of the Sahara (Chad, Mali, Mauritania and Niger). Between 1950 and 1980, the North African population grew at an average rate of $2.7 \%$, increasing from 29.0 million to 48.7 million (Figure 7). During the same time period, the population of the Sahel increased at an average annual rate of $2.0 \%$, going from 12.3 million to 18.6 million. The growth rates of the two regions begin to diverge starting in the 1990s. Between 1990 and 2010, the population of the Sahel increased at an average annual rate of 3.3\%, going from 23.7 million to 45.2 million, or close to double the population. The growth rate in North Africa dropped to 1.4\% between 2005 and 2010 before increasing slightly to $1.6 \%$ over the course of the past decade. 
Figure 7.

Demographic growth and total population of North Africa and the Sahel, 1950-2020

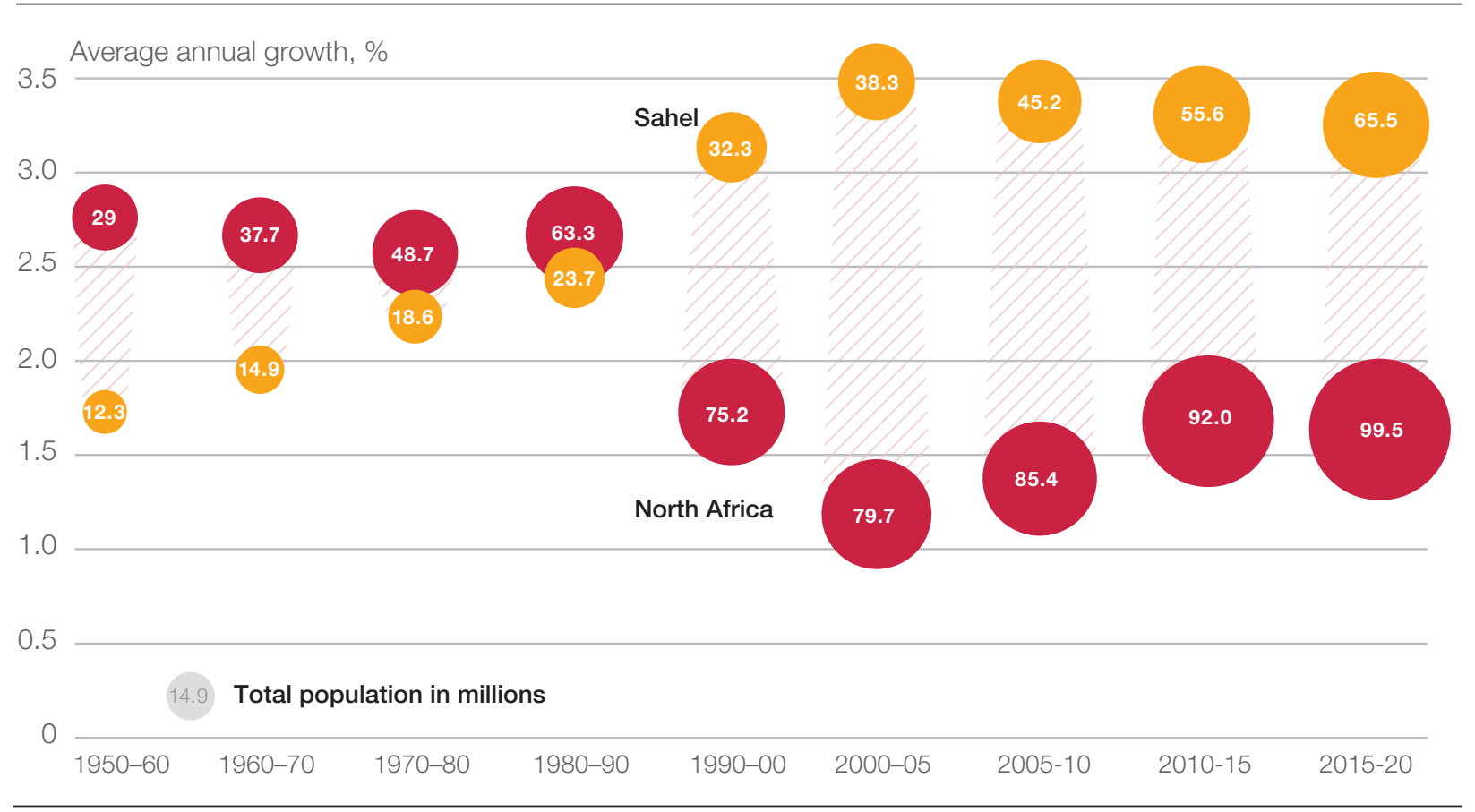

Note: The population data refer to the end of the specified time period.

Source: OECD/SWAC (2014[3]). Updated by the author using United Nations (2019[1]) data.

The per-country growth rates confirm the difference observed at the regional level between North Africa and the Sahel. (Figure 8). While the countries north of the Sahara were in the final phase of the demographic transition, Sahel countries were in the first or second phase, which is marked by strong growth. Between 1950 and 1980, the highest average annual growth rates were recorded first in Libya and Algeria, then in Mauritania and Niger. Starting in 1990, none of the North African countries had average annual growth rates above 3\%. On the contrary, the demographic change in the region was marked by a very significant decline in growth, dropping to $1.1 \%$ per year in Tunisia, 1.3\% in Morocco, 1.4\% in Libya, and 2.0\% in Algeria. The situation was reversed in the Sahel: the rate of demographic growth began to increase in all countries in the 1990s, peaking at $4.0 \%$ per year in Niger between 2010 and 2015, the highest rate recorded in the modern history of the Sahel. However, demographic growth has declined over the past five years and now sits at 2.8\% per year in Mauritania, 3.0\% in Mali, 3.3\% in Chad and 3.9\% in Niger. 
Figure 8.

Demographic growth rate per country, 1950-2020

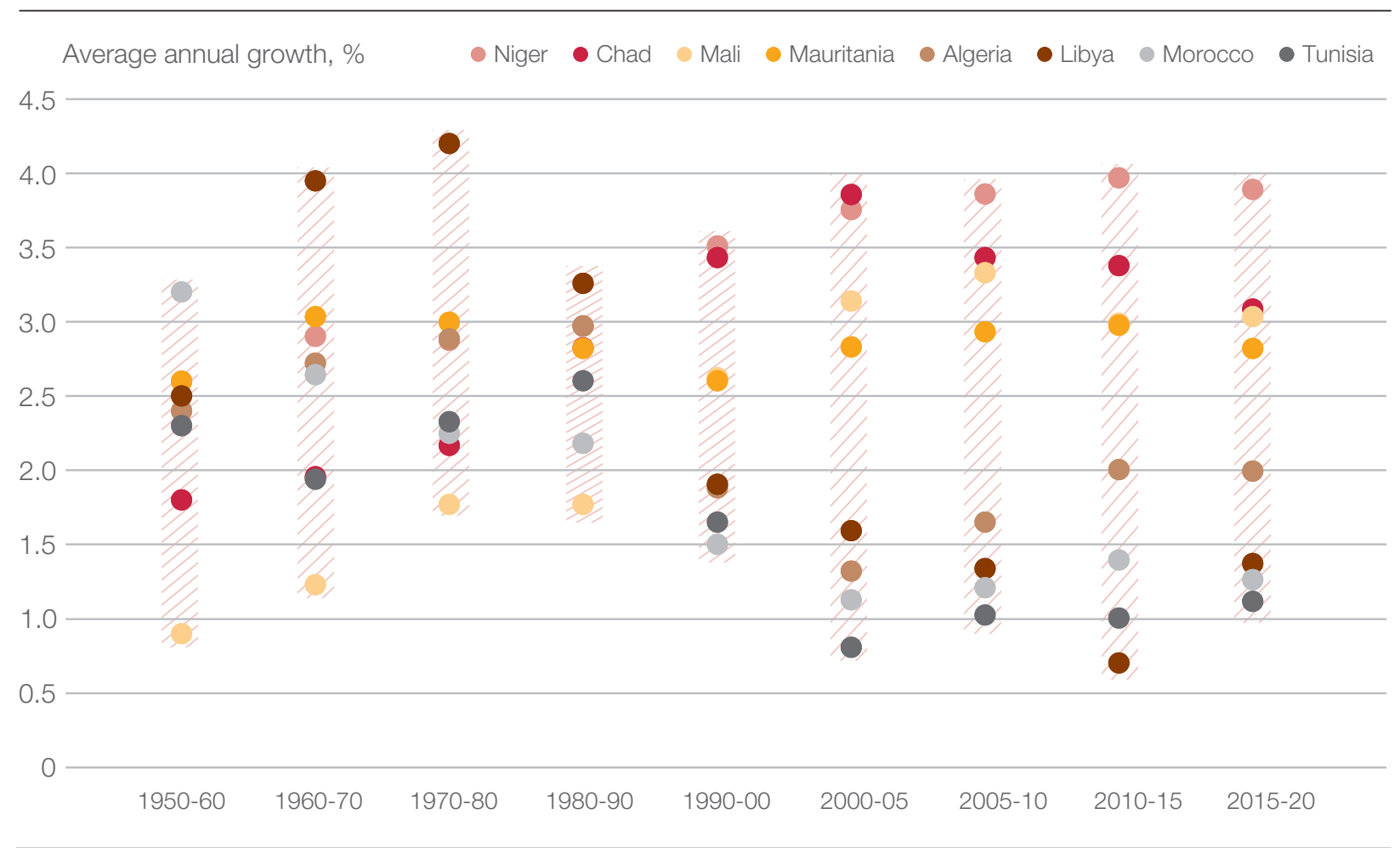

Note: The population figures reference the end of the specified time period.

Source: OECD/SWAC (2014[3]). Updated by the author using United Nations (2019[1]) data.

With close to 44 million inhabitants in 2020, Algeria is the region's most populated country (Figure 9). Morocco has been the second most populous since 1990; it had close to 37 million inhabitants in 2020. The vitality of the Algerian population is due to the uptick seen in fertility since the mid-2000s; this has resulted in an increase in the number of children per woman from 2.4 in 2005 to 3.1 in 2020. However, in Morocco the average fertility rate has been declining continuously since the 1960s. The exceptional growth of the Nigerien population is the reason why it has been the region's third most populous country, starting in the 1990s. The population was more than 24 million in 2020, as compared with less than 6 million in 1980. Over the past 20 years, both Chad and Mali have doubled their population, with over 16 and 20 million people, respectively, in 2020. With 12 million inhabitants, Tunisia has close to twice the population of Libya (7 million). Mauritania has a population of less than 5 million and remains the least populous country in the region. 
Figure 9.

Change in population per country (in millions)

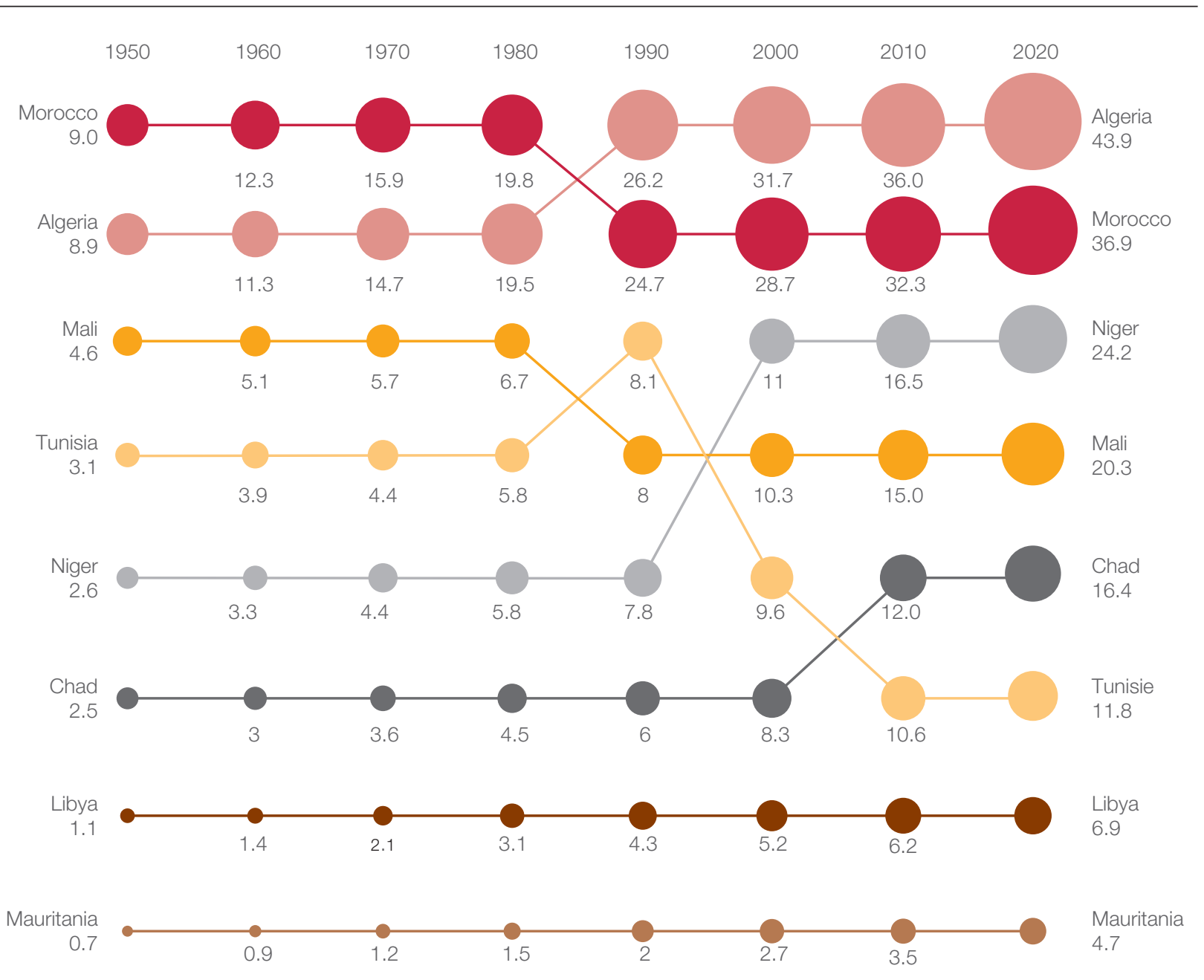

Source: OECD/SWAC (2014[3]). Updated by the author using United Nations (2019[1]) data. 


\section{A DROP IN THE FERTILITY RATE THROUGHOUT WEST AFRICA}

The fertility rates have dropped in all West African countries in recent decades. At the regional level, the number of children per woman dropped from 6.6 in 1960 to 6.0 in 2000 and to 4.7 in 2020. The countries can be split into three groups based on their demographic trajectory.

- In the most advanced countries undergoing the demographic transition, such as Cabo Verde, Côte d'Ivoire, Ghana, Liberia, Mauritania, Togo, and Senegal the decline in the fertility rate predates the 1980s (Figure 10). The number of children per woman dropped to 4.5 in 2020, with the exception of Cabo Verde, whose demographic profile is closer to that of North African countries with just over two children per woman.

Figure 10.

Fertility rates of the most advanced West African countries, 1960-2020

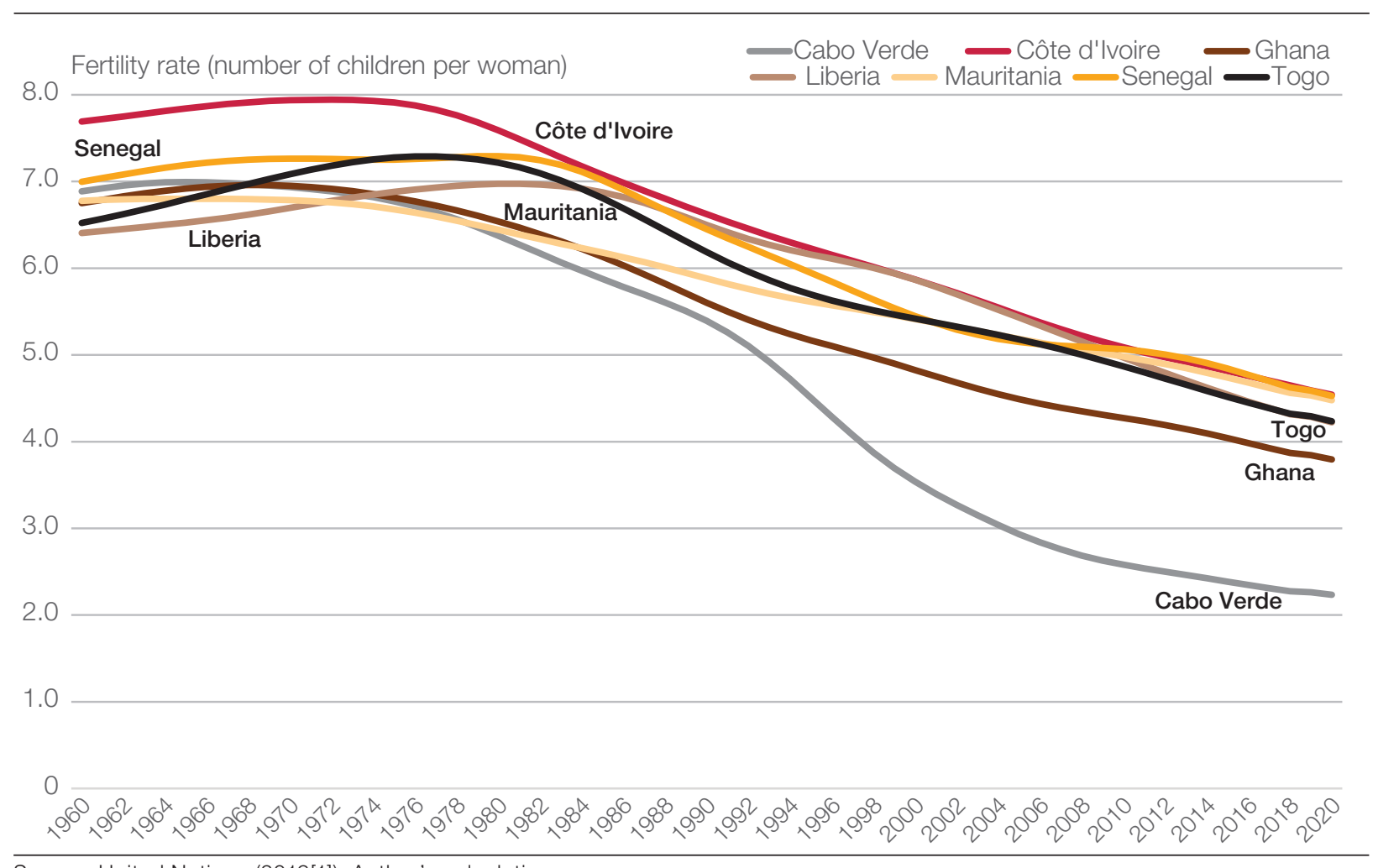

Source: United Nations (2019[1]). Author's calculations. 
- The beginning of the 1990s marked the beginning of declining fertility rates in a second group of countries that includes Benin, Burkina Faso, Gambia, Guinea, Guinea-Bissau, Nigeria, and Sierra Leone. In 30 years, the number of children per woman dropped from 6.5 to 4.5 (Figure 11).

- Fertility rates in Niger, Mali and Chad began to drop later, starting in the 2000s; they have been accelerating in the past few years. The most dramatic change was seen in Chad, where the number of children per woman went from 7.4 to 5.6 between 2000 and 2020 (Figure 11). Niger still has the highest fertility rate in the region, with 6.8 children per woman in 2020, a figure that represents a drop as compared with 2000 (7.7) and 2010 (7.5).

Figure 11.

Fertility rates of the least advanced West African countries, 1960-2020

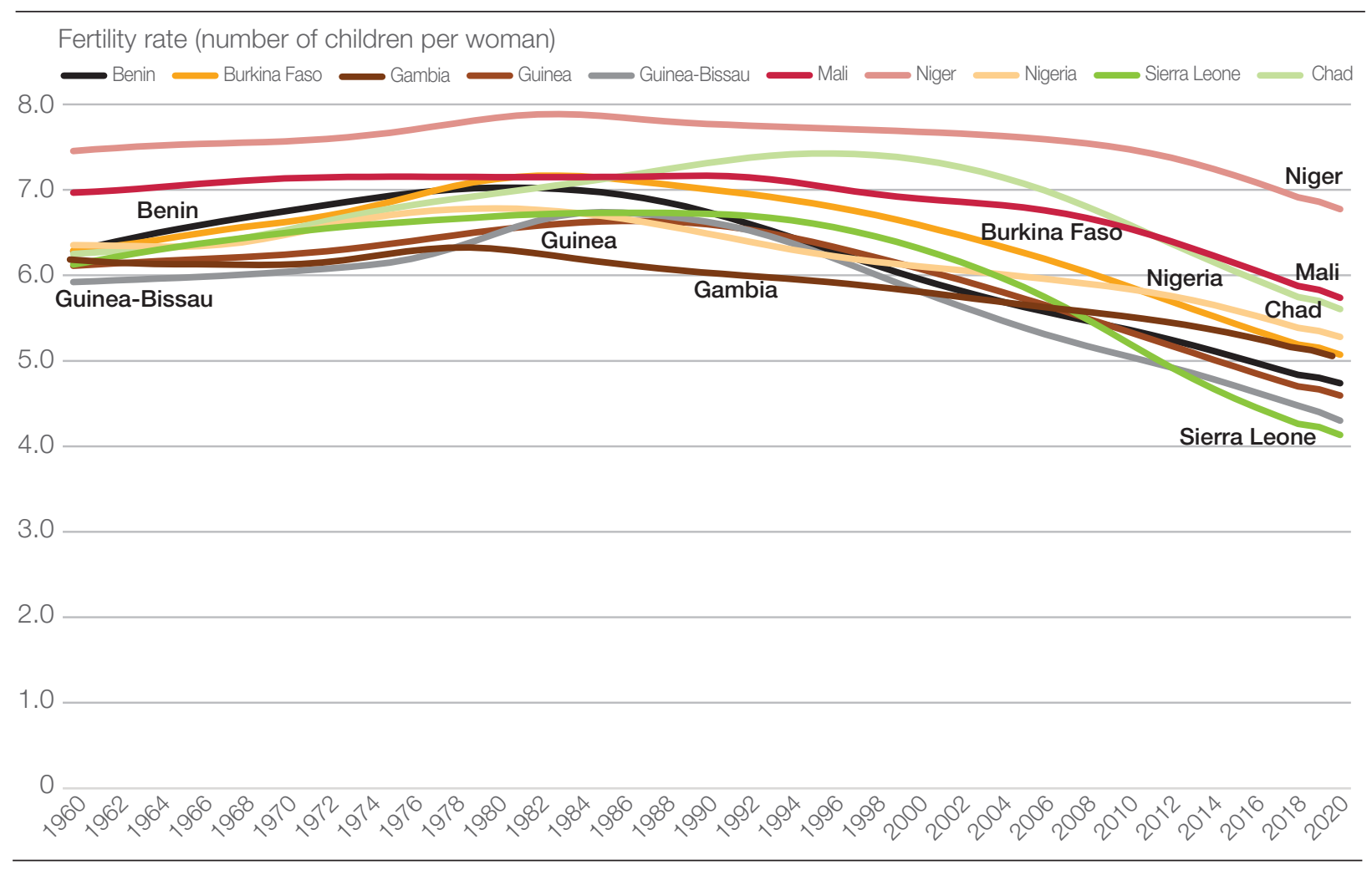

Source: United Nations (2019[1]). Author's calculations. 


\section{Demography and urbanisation}

Urbanisation is one of the most significant factors driving the drop in death and birth rates worldwide (Flückiger and Ludwig, 2017[10]; Gries and Grundmann, 2018[11]). Urban household members live longer and have fewer children than their rural counterparts. While urbanisation favours the demographic transition process, significant differences have been observed in the evolution of the population of sub-Saharan African cities, based on their size. The larger the city, the smaller the number of deaths. In addition, the families living in larger cities tend to have fewer children than those living in smaller ones (Corker, 2017[12]). These differences are especially significant in sub-Saharan Africa, where the vast majority of cities (97\%) have a population of less than 300000 people (OECD/SWAC, 2020[2]).

\section{DEMOGRAPHIC TRANSITION AND URBANISATION GO HAND IN HAND}

In North and West Africa, the most urbanised countries are, generally speaking, those with the smallest number of children per woman, as is the case in Libya, Algeria, Tunisia, Cabo Verde, and Morocco (Figure 12). On the other hand, the least urbanised countries still have very high fertility rates, such as Niger, Chad, and Burkina Faso. The statistical link between fertility and urbanisation is a substantial one: close to $70 \%$ of the variation in one of the variables is explained by the other $\left(\mathrm{R}^{2}=0.7\right)$.

Figure 12.

Fertility and urbanisation in North and West Africa, 2020

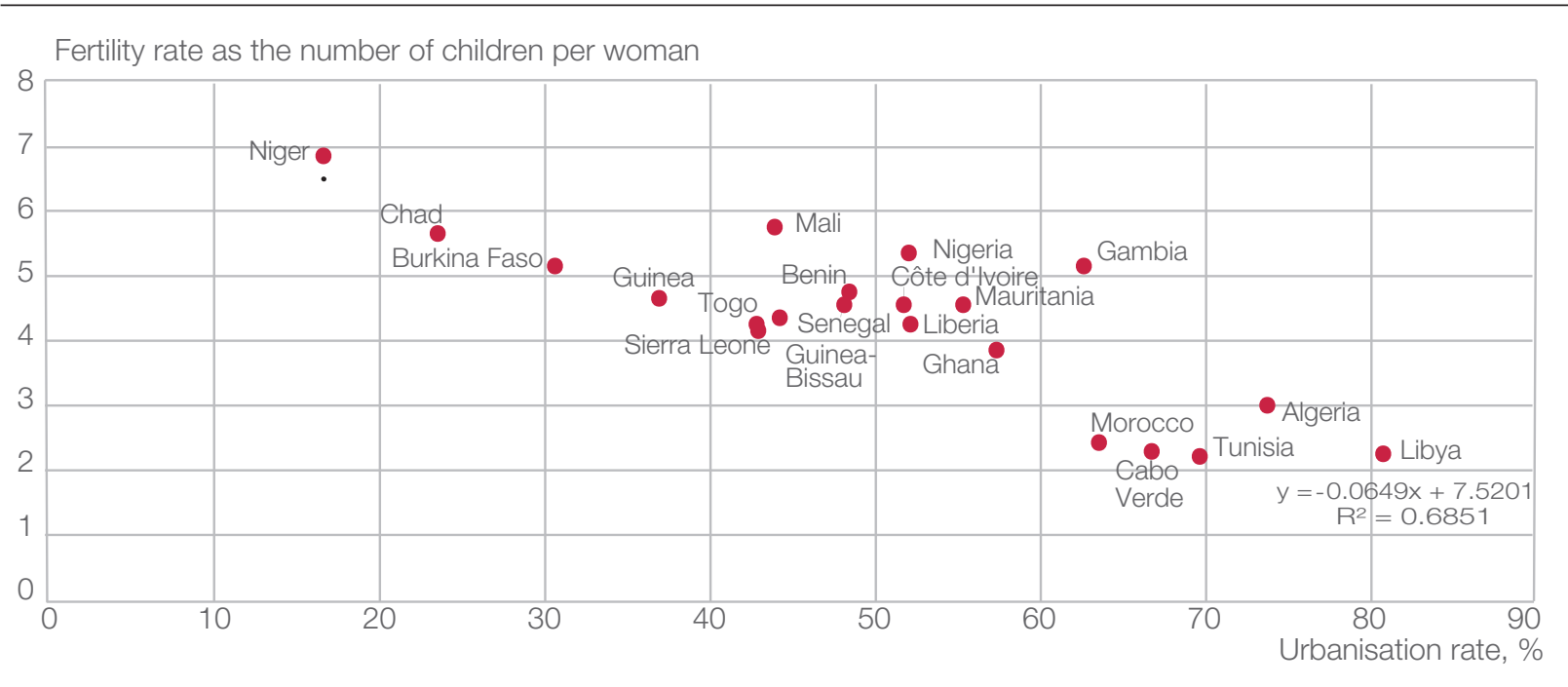

Source: United Nations (2019[1]). Author's calculations. 


\section{THE GROWTH OF URBANISATION}

Urban growth has profoundly changed the spatial distribution of the populations of North and West Africa in recent decades. In 2020, the rate of urbanisation in North Africa (including Egypt) was 70\%; it was 47\% in West Africa. In Algeria, Libya, and Tunisia, close to $75 \%$ of the population lives in an urban area, while less than $30 \%$ of the population in Chad and Niger lives in cities and towns (Figure 13).

\section{Figure 13.}

Urbanisation rate per country, 2020

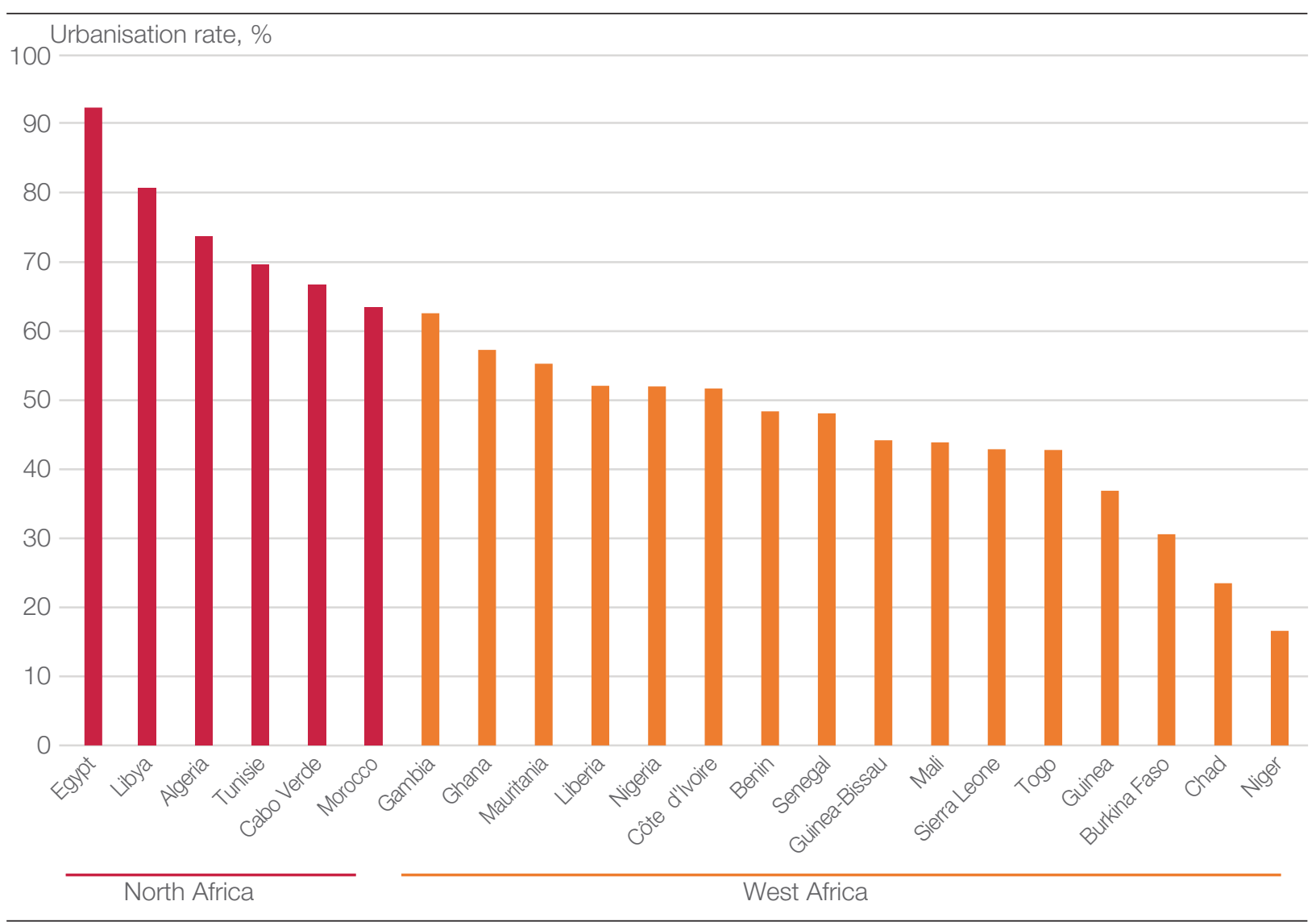

Sources: World Bank (2021[13]), OECD/SWAC (2020[2]). Author's calculations. 
The urbanisation rate in North Africa is 20\% higher than in West Africa (Figure 14). Since 1950, there has been a relatively constant gap between these two major regions.

Figure 14.

Regional urbanisation rates, 1950-2020

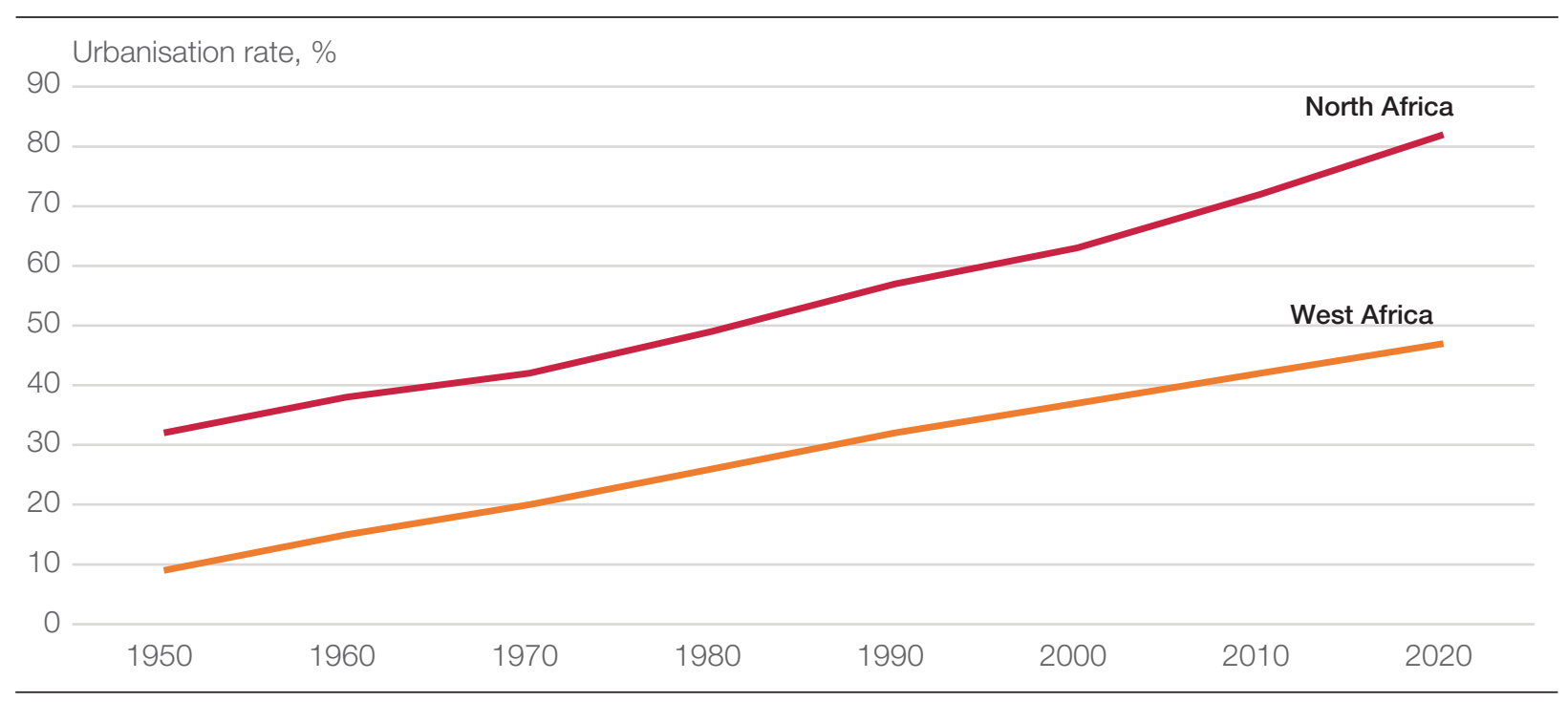

Sources: World Bank (2021[13]), OECD/SWAC (2020[2]). Author's calculations.

Over the course of the past 70 years, the population of urban areas has grown more rapidly than that of rural areas (Figure 15). In 2020, the number of urban dwellers approached the 200 million mark in the region, whereas the rural population is more than 220 million.

Figure 15.

Settlement dynamics in West Africa, 1950-2020

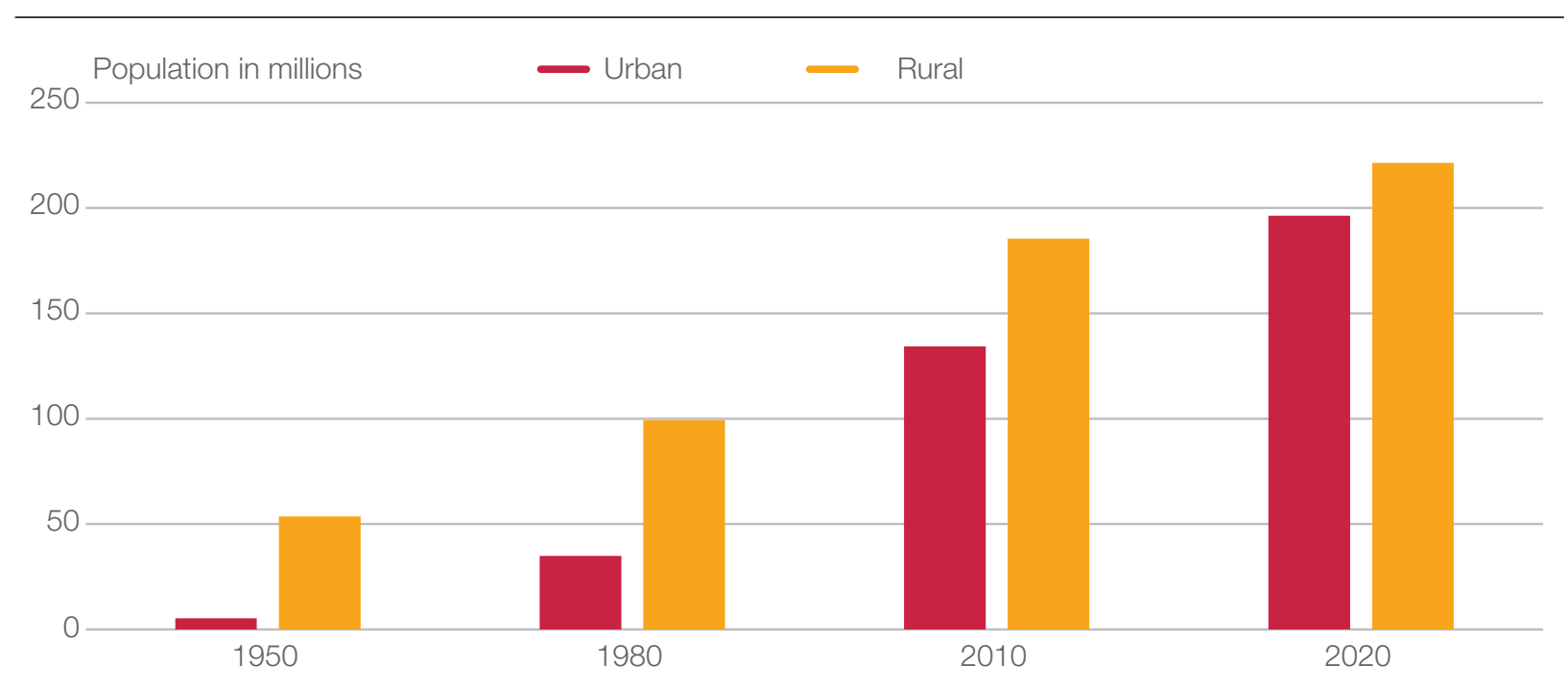

Note: Cabo Verde is not included in the analysis.

Source: OECD/SWAC (2014[3]). Updated by the author using World Bank (2021[13]) data. 
North of the Sahara, the urban population of Algeria, Morocco, Libya, and Tunisia is close to 70 million people. The urban growth these North African countries (+2.3\%) have experienced over the course of the decade is half as high as was recorded in the Sahel. South of the Sahara, the urban population of Mali, Mauritania, Niger, and Chad was estimated at more than 19 million people in 2020, with a sharp annual average increase going back to $2010(+5.2 \%)$.

Figure 16.

Urban population growth and figures per region, 1950-2020

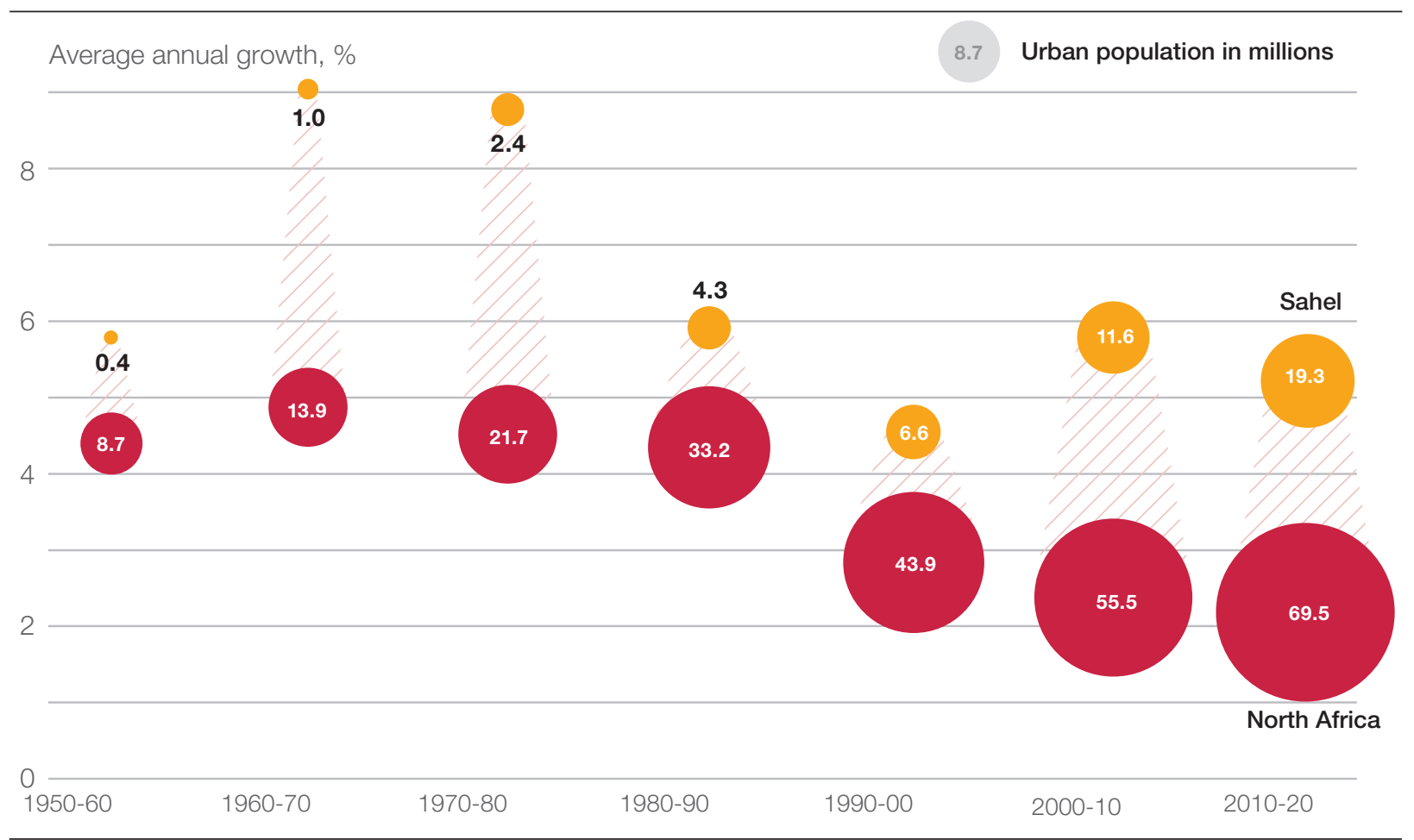

Note: The average annual growth rates reference the end of the specified time period.

Source: OECD/SWAC (2014[3]). Updated by the author using United Nations (2019[1]) data.

The Sahel is experiencing rapid urbanisation in conjunction with the continuous growth occurring in rural populations, which in 2020 accounted for some 46 million people, as compared with 26 million twenty years earlier (Figure 17). The growth rate in rural areas is close to $3 \%$ annually. In the four North African countries, the demographic growth was seen mostly in cities. In this region, the annual average growth rate of rural populations has been declining sharply since the end of the 1990s. It was negative between 2000 and 2010, and zero between 2010 and 2020. The absolute number of people in rural Algeria, Morocco, Libya, and Tunisia has been stagnant at about 30 million for the past twenty years. 
Figure 17.

Rural population growth and figures per region, 1950-2020

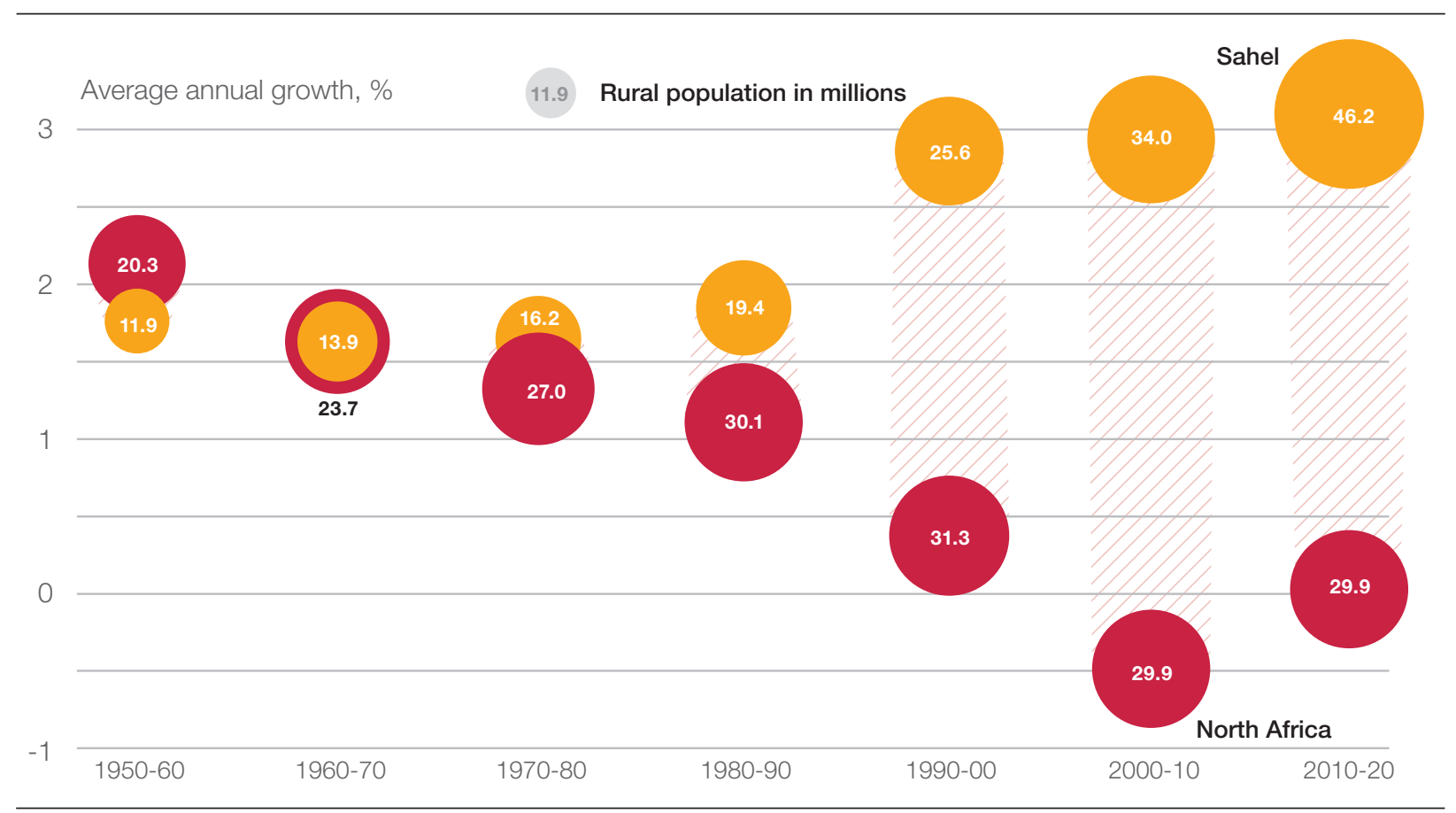

Note: The average annual growth rates reference the end of the specified time period.

Source: OECD/SWAC (2014[3]). Updated by the author using United Nations (2019[1]) data.

\section{CHANGES BY 2050}

By 2050, the population of the four Sahel countries should reach 141 million people, or about 10 million more than the four countries located north of the Sahara (Figure 18). In 30 years, the average annual growth rate should be just slightly more than $2 \%$ per year in the Sahel and just under $1 \%$ per year in North Africa. In both regions, the growth should be lower than the figures recorded up until 2020 due to the drop in the birth rate linked to the process of demographic transition. The gap between the growth rates of Sahel and North African countries will, however, persist.

The strong demographic growth seen south of the Sahara should result in some redistribution of the weighting of the region's countries by 2050 (Figure 19). With 61 million inhabitants, Niger will become the most populous country, edging slightly ahead of Algeria. Morocco will be the third most heavily populated country in North Africa, with more that 46 million people by 2050. The populations of Mali and Chad, with 40 and 31 million people respectively, will far outnumber that of Tunisia, whose population will be less than 14 million. 
Figure 18.

Population growth in the Sahel versus North Africa, 1950-2050

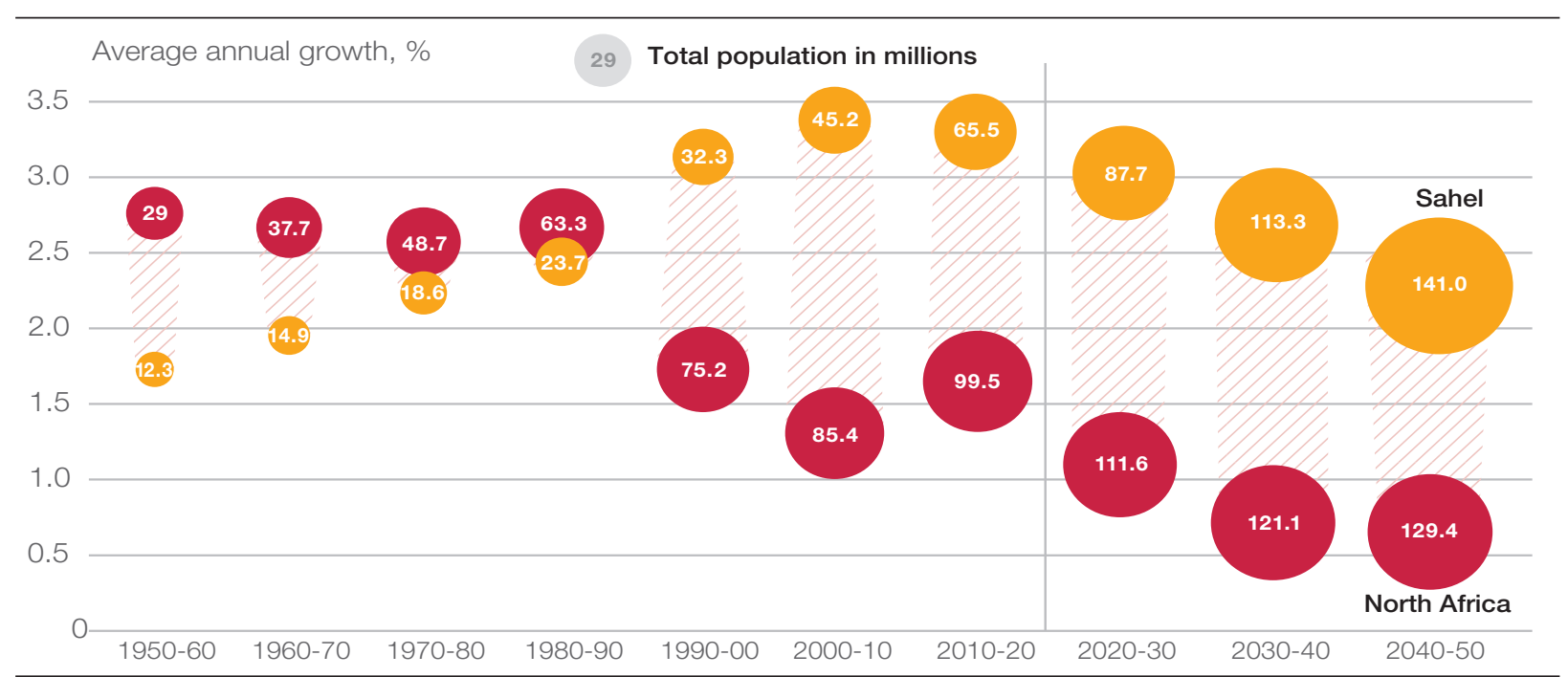

Note: The average annual growth rates reference the end of the time period concerned. Projections are low for the Sahel and average for North Africa. Source: OECD/SWAC (2014[3]). Updated by the author using United Nations (2019[1]) data.

Figure 19.

Projected number of inhabitants per country, 1950-2050 (in millions of people)

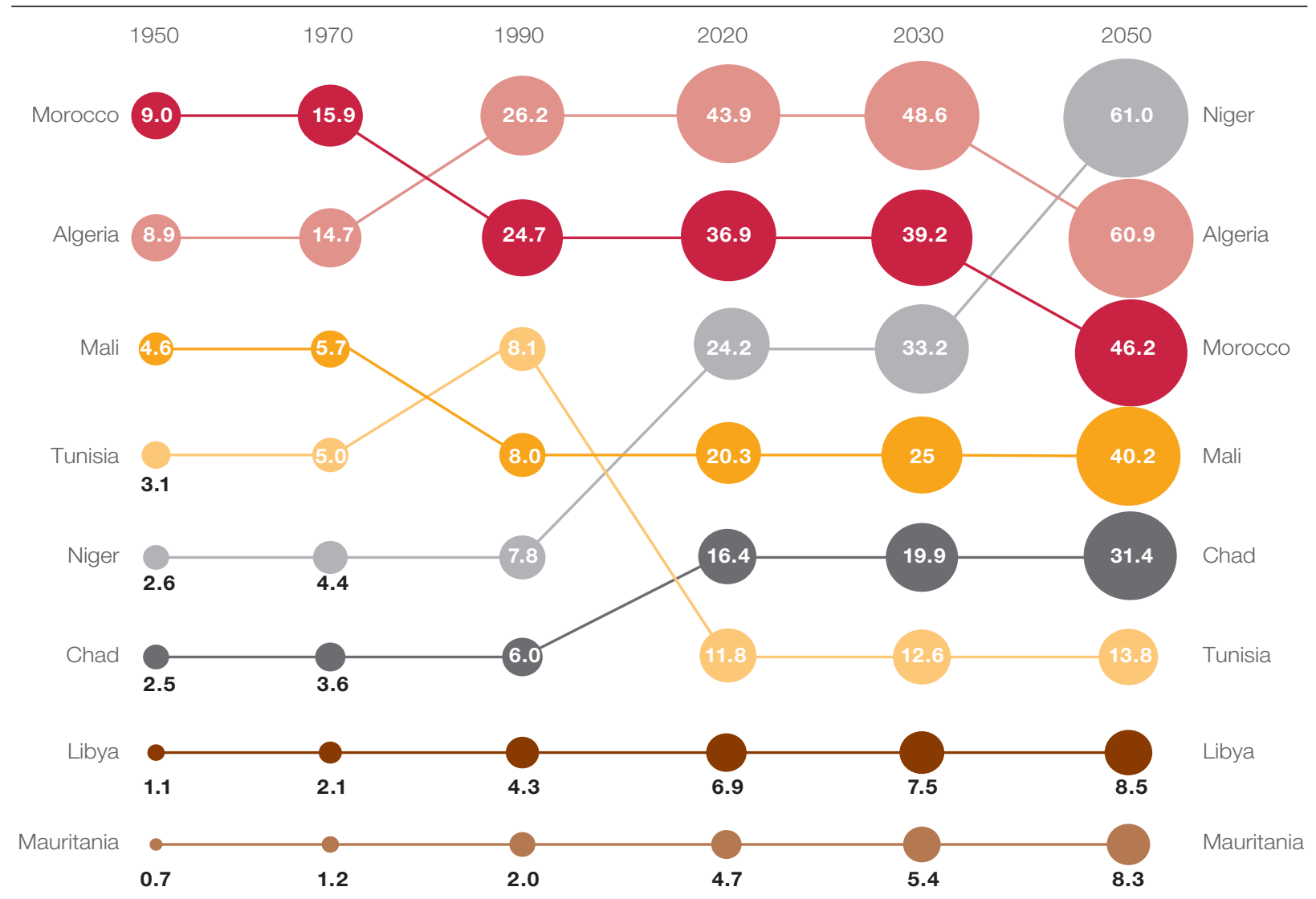

Note: The average annual growth rates reference the end of the specified time period. Projections are low for the Sahel and average for North Africa.

Source: OECD/SWAC (2014[3]). Updated by the author using United Nations (2019[1]) data. 


\section{Outlook}

North and West African countries are now fully involved in the process of demographic transition synonymous with declining birth and death rates. North of the Sahara, where the process is in the most advanced phase, the new demographic equilibrium features a birth rate than is higher than the theoretical model prediction, resulting in continuous population growth. South of the Sahara, all of the countries have seen the death rate plummet, followed by a decline in the birth rate. The discrepancy between the change in the two variables has contributed to spectacular natural growth in the space of a few decades. In this region, the most recent data suggest that the average annual population growth rate will slow to about $2 \%$ in 2050, while the current rate is $3 \%$. And so, it is likely that all countries will reach a new demographic equilibrium in the coming decades, including in the Sahel.

The significant demographic growth in the region is occurring in parallel with a redistribution of populations, to the benefit of urban areas which are becoming more populous due to natural growth and regional migration. North of the Sahara, more than $70 \%$ of the population now lives in cities and that percentage will continue to increase in the coming decades. South of the Sahara, where cities are quickly growing in number and size, close to half the people live in urban areas. West African urbanisation is likely to accelerate the social, economic and political changes that favour the demographic transition.

One of the main challenges facing the region is the question of how to reduce the regional variations seen in fertility rates, which are due to a time lag between the continent's urban and rural areas (Lerch, 2019[9]). Contraceptive techniques, new family standards and new technologies are spread from cities to the countryside at different speeds. Due to poor infrastructure quality, a low level of urbanisation, and a lack of strong public policies on family planning in many West African countries, fertility is declining more quickly in cities than in the countryside. The opposite is the case in other developing regions where a temporal convergence of rates is being seen. This is producing a disconnect between the demographic transition in cities and the same process in rural areas. 
Bongaarts, J. (2017), "Africa's Unique Fertility Transition", Population and Development Review, Vol. 43/S1, pp. 39-58, http://dx.doi.org/10.1111/j.1728-4457.2016.00164.x. [8]

Corker, J. (2017), "Fertility and Child Mortality in Urban West Africa: Leveraging Geo-Referenced Data to Move Beyond the Urban/Rural Dichotomy", Population, Space and Place, Vol. 23/3, p. e2009, http://dx.doi.org/10.1002/psp.2009. [12]

Doignon, Y. (2020), “Les transitions démographiques des pays méditerranéens depuis 1950”, Géoconfluences. [7]

Flückiger, M. and M. Ludwig (2017), "Urbanization, fertility and child education in SubSaharan Africa", Economics Letters, Vol. 157/C, pp. 97-102, http://dx.doi.org/10.1016/j. econlet.2017.05.024. [10]

Gries, T. and R. Grundmann (2018), "Fertility and modernization: The role of urbanization in developing countries", Journal of International Development, Vol. 30/3, pp. 493-506, http:// dx.doi.org/10.1002/jid.3104. [11]

Lerch, M. (2019), "Fertility decline in urban and rural areas of developing countries", Population and Development Review, Vol. 45/2, pp. 301-320, http://dx.doi.org/10.1111/padr.12220. [9]

Moriconi-Ebrard, F., D. Harre and P. Heinrigs (2016), Urbanisation Dynamics in West Africa 1950-2010: Africapolis I, 2015 Update, West African Studies, OECD Publishing, Paris, https:// dx.doi.org/10.1787/9789264252233-en. [5]

OECD/SWAC (2020), Africa's Urbanisation Dynamics 2020: Africapolis, Mapping a New Urban Geography, West African Studies, OECD Publishing, Paris, https://dx.doi.org/10.1787/ b6bccb81-en. [2]

OECD/SWAC (2014), An Atlas of the Sahara-Sahel: Geography, Economics and Security, West African Studies, OECD Publishing, Paris, https://dx.doi.org/10.1787/9789264222359-en. [3]

OECD/SWAC (2013), Settlement, Market and Food Security, West African Studies, OECD Publishing, Paris, https://dx.doi.org/10.1787/9789264187443-en. [4]

Our World in Data (2021), World Population Growth, https://ourworldindata.org/world-populationgrowth. [6]

United Nations (2019), World Population Prospects 2019, United Nations, Department of Social and Economic Affairs, Population Division. [1]

World Bank (2021), Population Estimates and Projections, The World Bank. [13] 


\section{West African Papers}

\section{Urbanisation and demography in North and West Africa, 1950-2020}

This brief presents a factual and retrospective analysis of the relationships between urbanisation and demography in North Africa and West Africa. It shows that the process of demographic transition is now fully underway in this region. North of the Sahara the new demographic equilibrium features a birth rate higher than expected, according to theoretical model predictions, resulting in continuous population growth. Over $70 \%$ of the population now lives in cities, a number that is expected to continue to rise in the coming decades. South of the Sahara all countries have seen death rates plummet, followed by a decrease in birth rates. The gap between the change in the two variables has contributed to spectacular natural growth in the space of a few decades. This growth is occurring in parallel with a redistribution of populations to urban areas, which are now home to close to one of every two inhabitants. West African urbanisation is likely to accelerate the social, economic and political changes that favour the demographic transition. One of the main challenges facing the region is the question of how to reduce the regional variations seen in fertility rates between the continent's urban and rural areas.

This work is published on the OECD iLibrary, which gathers all OECD books, periodicals and statistical databases. Visit www.oecd-ilibrary.org for more information. 